\title{
Synthesis, Characterization and DFT investigation of New Metal Complexes of Ni(II), Mn(II) and VO(IV) Containing N,O-donor Schiff Base Ligand
}

\author{
Djouhra AGgOUN ${ }^{\text {a,b,* }}$, Zakia MESSASMA ${ }^{\mathrm{a}, \mathrm{b}}$, Brahim BOUZERAFA ${ }^{\mathrm{c}}$, Raúl BERENGUER ${ }^{\mathrm{d}}$, \\ Emilia MORALLON ${ }^{d}$, Yasmina OUENNOUGHI a and Ali OURARI ${ }^{\text {a }}$ \\ ${ }^{a}$ Laboratoire d'Electrochimie, d'Ingénierie Moléculaire et de Catalyse Redox (LEIMCR), Faculté de \\ Technologie, Université Ferhat ABBAS de Sétif-1, Sétif 19000, Algeria. \\ ${ }^{b}$ Département de chimie, Faculté des sciences, Université Ferhat ABBAS de Sétif-1, Sétif 19000, \\ Algeria. \\ ${ }^{c}$ Laboratoire de Préparation, Modification des Matériaux Polymériques Multiphasiques (LMPMP), \\ Faculté de Technologie, Université Ferhat ABBAS Sétif-1, 19000 Sétif, Algeria. \\ ${ }^{d}$ Departamento de Química Física, Instituto Universitario de Materiales, Universidad de Alicante (UA), \\ Ap.99, 03080 Alicante, Spain.
}

\begin{abstract}
In this work, a bidentate Schiff base ligand (HL) based on $\mathrm{N}$ and $\mathrm{O}$ donor heteroatoms has been used to synthesize a series of new stable metal complexes of general composition of $\mathbf{M}(\mathbf{L})_{2}$ with $\mathbf{M}=\mathrm{Mn}$, Ni and VO. The ligand was obtained from the condensation of 2-methoxybenzylamine with 2,3dihydroxybenzaldehyde in methanolic medium. The complexes were formed by mixing the metal acetate salts and the ligand in 1:2 molar ratio. The resulting three complexes have been characterized by different analytical techniques, including FT-IR, UV-Vis, mass spectroscopies, thermogravimetry and cyclic voltammetry, to study their molecular structure and redox/electrochemical properties. Moreover, the effect of the metal on the complexes electronic properties, and their predicted reactivity, has been studied by Density Functional Theory (DFT). The spectroscopic results suggest that the metal is bonded to the ligand through the phenolic-like oxygen and the imine-type nitrogen atoms. Electronic and vibrational absorption spectra of the nickel complex suggest a square-planar geometry around the central metal ion Ni(II), while square-pyramidal and octahedral geometry have been proposed for VO(IV) and Mn(II) complexes. The thermogravimetric analyses of the complexes confirmed the presence of water molecules in their structures and thermal decomposition led to the formation of metal oxides as residues. The voltammogram of the Ni(II) complex suggests the existence of quasi-reversible redox system in DMSO solution.
\end{abstract}

Keywords: N,O donors; Bis-bidentate Schiff base complexes; Spectral studies; Cyclic voltammetry; Thermogravimetry. DFT Calculations. 
- Corresponding author. Tel: +213.697.78.81.45

E-mail address: aggoun81@yahoo.fr (Dj. AGGOUN).

\section{Introduction}

In recent decades, Schiff bases ligands [1] have attracted lot of attention not only for their structural variety (fundamental research), but also for their various physicochemical properties opening a wide domain of applications (practical point of view) [2]. This interest is also due to the structural versatility of Schiff bases to conform asymmetric compounds (Katsuki and Jacobsen), stabilizing many different complexes in various oxidation states and controlling the performance of metals in a large variety of useful transformations [3,4]. Moreover, the coordination geometry of these complexes $[\mathbf{5 , 6}]$ depends upon various factors, including the size of coordination sphere, electronic configuration of the central metal ions, non-bonding interactions between atoms in different ligands accompanied with inherent rigidity due to the presence of aromatic rings.

Since they are getting increasing significance as analytical and electroanalytical reagents $[\mathbf{7 , 8}]$, transition metal complexes employing Schiff base as ligands are among the most interesting coordination compounds in the past few years. Their importance was also clearly proved from their good catalytical activities in numerous photochemical, chemical or electrochemical reactions [9-13]. Especially, transition metal complexes with N,O-chelating Schiff bases derived from salicylaldehyde are of particular interest[14-16]. They are essential in organic chemistry as starting compounds, synthetic intermediates and designer molecules and, therefore, in the field of materials science and industry of chemicals and bioactive compounds. In addition, they have played a seminal role in the development of modern coordination chemistry, but they could play also a crucial role in the development of inorganic chemistry. The design of new bidentate Schiff base ligands containing $\mathrm{N}$ and $\mathrm{O}$ atoms or functional groups with electron donor capability is then very interesting for metal complexation application. These ligands can be prepared by condensation of aldehydes with primary amines. Among different possibilities, we have previously reported the synthesis of novel N,O-donor Schiff base ligands from the combination of benzaldehydes with phenylamines [5,14-16]. The donor capability of these ligands can be further tailored by modifying the nature and relative position of different substituents in these precursors. Hence, new metal complexes exhibiting different properties can be derived from these new ligands. In a previous work, we demonstrated that a Schiff base ligand obtained from 2-methoxybenzylamine and 2,3dihydroxybenzaldehyde can effectively complex and detect $\mathrm{Cu}^{2+}, \mathrm{Co}^{2+}, \mathrm{Fe}^{2+}$ and $\mathrm{Fe}^{3+}$ ions by color 
changes [5]. Despite not studied yet, this type of Schiff base ligands could also form interesting complexes with other redox active species.

Continuing our efforts in the synthesis and study of new transitions metal complexes, this work reports the synthesis and physicochemical and electrochemical characterization of three new complexes of $\mathrm{Ni}$ (II), $\mathrm{Mn}(\mathrm{II})$ and $\mathrm{VO}(\mathrm{IV})$ (oxovanadium) derived from 2-methoxybenzylamine and 2,3dihydroxybenzaldehyde. Specifically, the study is essentially focused on elucidating the molecular structure and geometry as well as redox properties of these complexes.

\section{Experimental}

\subsection{Materials}

All the chemicals were purchased from commercial sources and used without any further purification. The purity of the synthesized compounds was checked by thin-layer chromatography (TLC) using glass plates precoated with silica gel (60F; Merck).

\subsection{Synthesis of the Schiff base ligand and metal complexes}

The Schiff-base N (imine), O-donor ligand (HL) was prepared according the literature [5]. Briefly, 1 mmol of 2-methoxyphenylmethylamine was mixed with $1 \mathrm{mmol}$ of the 2,3-dihydroxybenzaldehyde in methanol $(10 \mathrm{~mL})$. The resulting solution was refluxed for ca. $2 \mathrm{~h}$ and allowed to cool. The yellow powder ligand was used to form new metal complexes.

For the synthesis of the complexes, the required weights of the acetate salts of $\mathrm{Ni}(\mathrm{II})$ $\left(\mathrm{Ni}\left(\mathrm{CH}_{3} \mathrm{COO}\right)_{2} \cdot 4 \mathrm{H}_{2} \mathrm{O}\right), \mathrm{Mn}(\mathrm{II})\left(\mathrm{Mn}\left(\mathrm{CH}_{3} \mathrm{COO}\right)_{2} \cdot 4 \mathrm{H}_{2} \mathrm{O}\right)$ and $\mathrm{VO}(\mathrm{IV})\left(\mathrm{VO}\left(\mathrm{CH}_{3} \mathrm{COO}\right)_{2}\right)$, dissolved in absolute $\mathrm{MeOH}$, were added to a boiling solution of the imine ligand (HL) in absolute $\mathrm{MeOH}$ in 1:2 molar ratio of metal and ligand, respectively. This molar ratio was chosen to form $\mathrm{ML}_{2}$ complexes. The resulting mixture was stirred under reflux for $4 \mathrm{~h}$, whereupon the complexes precipitated. The obtained powders were collected by filtration, washed several times with ethanol and then with diethylether to remove any traces of unreacted starting materials, and finally dried in a vacuum desiccator, which leads to the target metal complexes. The synthesis of the different complexes and their molecular structure, as proposed from the data obtained in this work (see section 3), are shown in Scheme 1. 


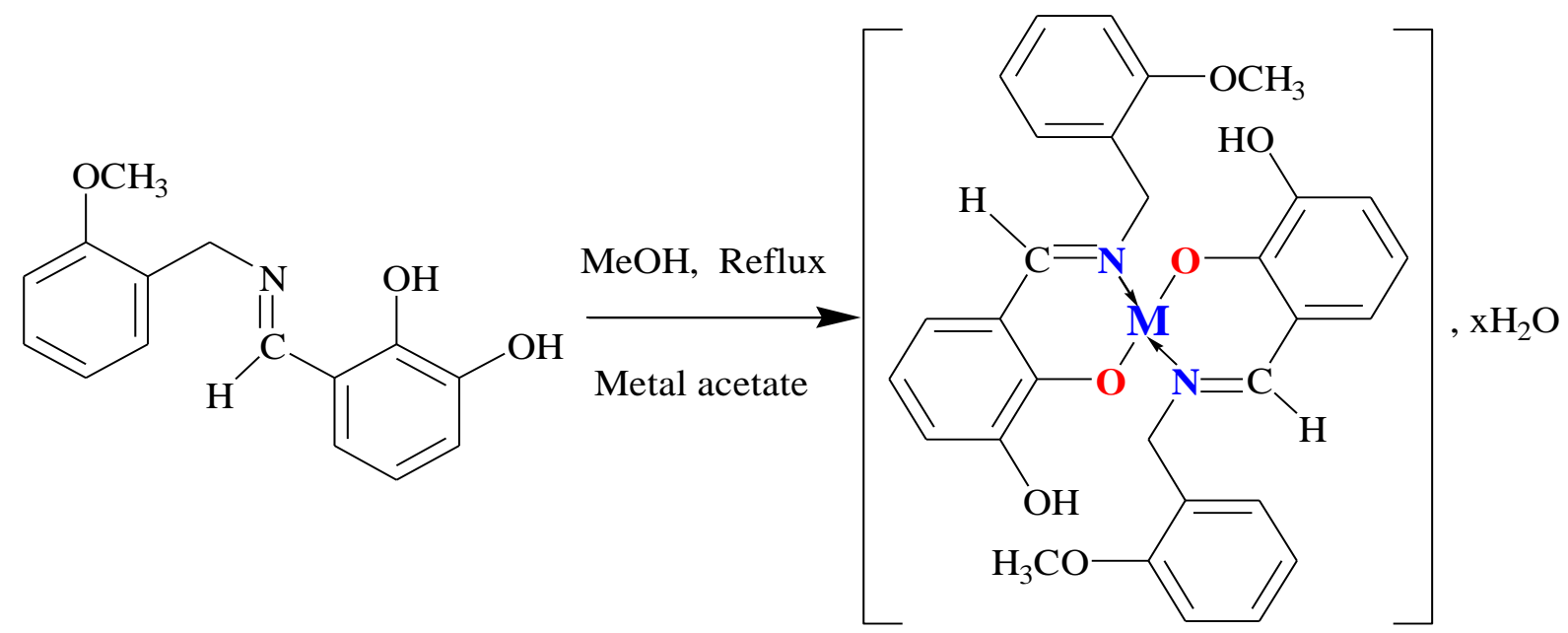

$M=N i, M n$ and $V O$

$\mathrm{M}(\mathrm{L})_{2} \cdot \mathbf{x ~ H}_{\mathbf{2}} \mathbf{O}$
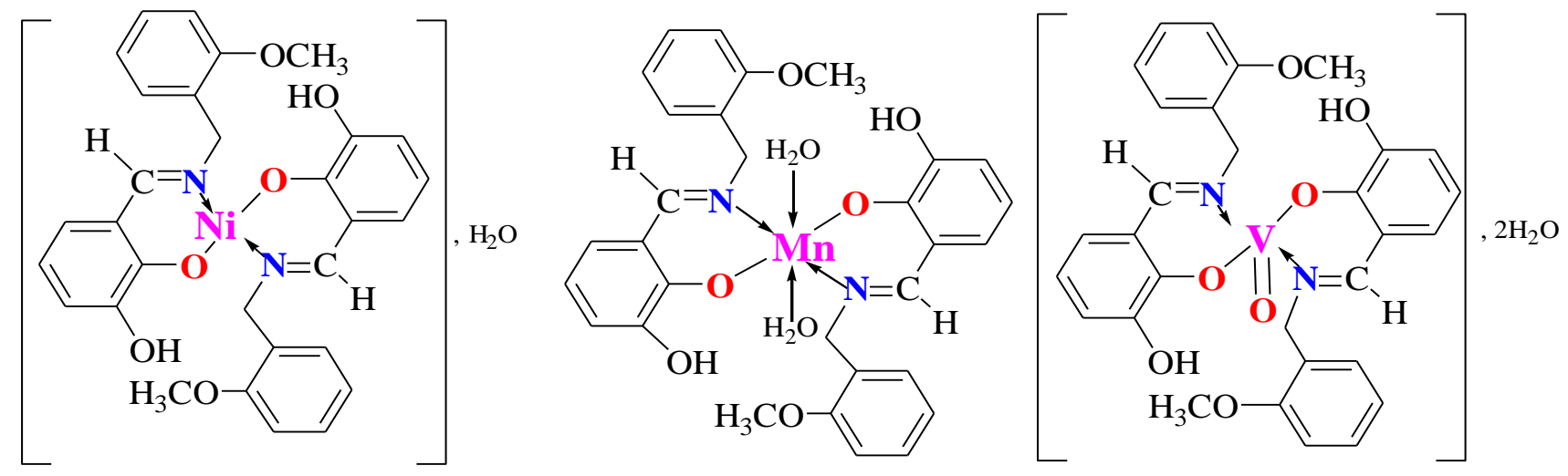

Scheme 1. Scheme of the synthesis of new complexes of $\mathrm{Ni}(\mathrm{II}), \mathrm{Mn}$ (II) and VO(IV) with the bidentate Schiff-base ligand.

\subsection{Physico-chemical and electrochemical characterization}

The obtained complexes were characterized by elemental analysis by using a (C, N, H, S) LECO analyzer (Micro TruSpec model). This analysis was repeated three times to confirm the reproducibility of the results.

FT-IR spectra of the complexes were recorded by preparing KBr pellets on a Perkin-Elmer 1000 FTIR Spectrophotometer. UV-visible spectroscopy was carried out in DMF solutions on a UNICAM UV-300 spectrophotometer (path length of the cell, $1 \mathrm{~cm}$ ). For mass spectrometry (LC-MS), a HPLC Agilent 1100 series coupled to UV-Vis and MS with ionic tramp detector (Agilent model 1100 Series LC/MSD Trap SL) was used. 
Thermal analysis (TG and DTG) of the complexes was obtained under nitrogen atmosphere using a TGA Perkin Elmer thermal analyzer. The heating rate was set at $10{ }^{\circ} \mathrm{C} \mathrm{min}-1$ and the weight loss was measured from $25^{\circ} \mathrm{C}$ up to $950^{\circ} \mathrm{C}$.

Cyclic voltammetry was utilized to study the redox and electrochemical properties of the complexes. The experiments were carried out in an undivided Metrohm cell of $5 \mathrm{~cm}^{3}$ using a Voltalab 40 (potentiostat/galvanostat) PGZ 301 A 0.1 M tetra-n-butylammoniumtetrafluoroborate $\left(\mathrm{TBABF}_{4}\right)$ solution in dimethyl sulfoxide (DMSO) was used as supporting electrolyte in all the electrochemical experiments. The planar tip of a glassy carbon $(\mathrm{GC})$ bar $(\varnothing, 3 \mathrm{~mm})$ was used as the working electrode, a platinum wire $(\mathrm{Pt})$ as the auxiliary electrode and all the electrode potentials were referred versus as saturated calomel electrode (SCE) reference electrode. Furthermore, the influence of different scan rates: 25, 50, 75, 100, 200, 300, 400 and $500 \mathrm{mV} / \mathrm{s}$, has been studied.

\subsection{Computational study}

Theoretical calculations for HL ligand and its Ni(II), Mn(II) and VO(IV) complexes were performed using the Gaussian 09 program, based on Density Functional Theory (DFT) [19], using Beck's three parameter hybrid exchange functional [20], with Lee-Yang-Parr correlation functional (B3LYP) and 6$31 \mathrm{G}(\mathrm{d}, \mathrm{p})$ basis set $[\mathbf{2 1 , 2 2}$. In order to make comparative study between the ligand and their complexes with the optimized configurations, HOMO, LUMO, gap properties and Energy calculations for the compounds were useful to determine binding sites and predicting the reactivity of the compounds. The Molecular electrostatic potential (MEP) and the global reactivity descriptors of the molecules were also performed by the DFT.

\section{Results and discussion}

\subsection{Physico-chemical properties and molecular formula of the complexes}

The obtained complexes were intensively colored, stable in air and moisture free powder solids. The $\mathrm{Ni}(\mathrm{II}), \mathrm{Mn}(\mathrm{II})$, and $\mathrm{VO}(\mathrm{IV})$ complexes were not soluble in most common solvents, such as water, methanol, ethanol, ethyl acetate and acetonitrile. However, they were fairly soluble in N,N-dimethyl formamide (DMF) and dimethyl sulfoxide (DMSO). Table 1 summarizes some of the physico-chemical properties and molecular formulae of the complexes. As it can be deduced from this table, the results of elemental analysis (measured) were found in good agreement with those calculated from the proposed molecular formulae for the different complexes. 
$\mathbf{N i}^{\mathrm{II}}(\mathbf{L})_{2} \cdot \mathbf{H}_{2} \mathrm{O}$ : Anal. Calc. for $\mathbf{C}_{30} \mathbf{H}_{30} \mathbf{N}_{2} \mathbf{O}_{7} \mathbf{N i}: \mathbf{C} 61.15 ; \mathbf{H} 5.13 ; \mathbf{N} 4.75$ Found: $\mathbf{C} 60.84 ; \mathbf{H} 4.88 ; \mathbf{N} 4.68$ $\%$. UV-Vis (DMF): $\lambda_{\max (\mathrm{n})}(\mathrm{nm}), \varepsilon_{\max (\mathrm{n})}\left[\mathrm{M}^{-1} \cdot \mathrm{cm}^{-1}\right]: \lambda_{\max (1)}(276), \varepsilon_{\max (1)}[16250] ; \lambda_{\max (2)}(380), \varepsilon_{\max (2)}$ [3820]. (MS-LC): (m/z) $571.1\left(\left[\mathrm{NiL}_{2}\right]^{+}\right)$.

$\mathbf{M n}^{\mathrm{II}}(\mathbf{L}) 2 \cdot 2 \mathrm{H}_{2} \mathrm{O}$ : Anal. Calc. for $\mathbf{C}_{30} \mathbf{H}_{32} \mathbf{N}_{2} \mathbf{O} \mathbf{8} \mathbf{M n}$ : C 59.70; H 5.34; N 4.64 Found: C 60.27; $\mathbf{H}$ 4.43; $\mathbf{N}$ $4.23 \%$. UV-Vis (DMF): $\lambda_{\max (\mathrm{n})}(\mathrm{nm}), \varepsilon_{\max (\mathrm{n})}\left[\mathrm{M}^{-1} \cdot \mathrm{cm}^{-1}\right]: \lambda_{\max (1)}(329), \varepsilon_{\max (1)}$ [10600]; $\lambda_{\max (2)}(585), \varepsilon_{\max (2)}$ [890]. (MS-LC): $(\mathrm{m} / \mathrm{z}) 569.4\left(\left[\mathrm{MnL}_{2}+2 \mathrm{H}^{+}\right]\right)$.

$\mathbf{V O}^{\mathbf{I V}}(\mathbf{L})_{2} \cdot \mathbf{2 H}_{2} \mathbf{O}$ : Anal. Calc. for $\mathbf{C}_{30} \mathbf{H}_{32} \mathbf{N}_{2} \mathbf{O} 9 \mathbf{V}$ : C 58.54; $\mathbf{H}$ 5.24; $\mathbf{N} 4.55$ Found: $\mathbf{C} 58.08 ; \mathbf{H} 4.62 ; \mathbf{N} 3.47$ \%. UV-Vis (DMF): $\lambda_{\max (\mathrm{n})}(\mathrm{nm}), \varepsilon_{\max (\mathrm{n})}\left[\mathrm{M}^{-1} \cdot \mathrm{cm}^{-1}\right]: \lambda_{\max (1)}(269), \varepsilon_{\max (1)}$ [18600]; $\lambda_{\max (2)}(310), \varepsilon_{\max (2)}$ [15830]; $\lambda_{\max (3)}$ (430), $\varepsilon_{\max (3)}$ [4560]. (MS-LC): (m/z) $580.7\left(\left[\mathrm{VOL}_{2}+\mathrm{H}^{+}\right]\right)$.

Table 1. Physico-chemical properties and proposed molecular formulae of the synthesized nickel(II), manganese(II) and oxovanadium(IV) complexes.

\begin{tabular}{|c|c|c|c|c|c|c|c|c|}
\hline \multirow{3}{*}{$\begin{array}{c}\text { Complex } \\
\mathbf{N i}^{\mathrm{II}}(\mathbf{L})_{2} \cdot \mathbf{H}_{2} \mathbf{O}\end{array}$} & \multirow{3}{*}{\begin{tabular}{|l}
$\lambda_{\max (\mathrm{n})}$ \\
$(\mathrm{nm})^{\mathrm{a}}$
\end{tabular}} & \multirow{3}{*}{$\begin{array}{c}\begin{array}{c}\varepsilon_{\max (\mathrm{n})} \\
\left(\mathrm{M}^{-1} \cdot \mathrm{cm}^{-1}\right)^{\mathrm{b}}\end{array} \\
\text { (1) } 16250 \\
\text { (2) } 3820\end{array}$} & & & \multicolumn{3}{|c|}{ Elemental analysis $\mathbf{d}$} & \multirow[b]{2}{*}{$\begin{array}{l}\text { Molecular } \\
\text { formula }\end{array}$} \\
\hline & & & \multicolumn{2}{|c|}{ LC-MS $(\mathrm{m} / \mathrm{z})^{\mathrm{c}}$} & $\mathrm{C}(\%)$ & $\mathrm{H}(\%)$ & $\mathrm{N}(\%)$ & \\
\hline & & & 571.1 & {$\left[\mathrm{NiL}_{2}\right]^{+}$} & $\begin{array}{c}60.84 \\
(61.15)\end{array}$ & $\begin{array}{c}4.88 \\
(5.13)\end{array}$ & $\begin{array}{c}4.68 \\
(4.75)\end{array}$ & $\mathrm{C}_{30} \mathrm{H}_{30} \mathrm{~N}_{2} \mathrm{O}_{7} \mathrm{Ni}$ \\
\hline $\mathrm{Mn}^{\mathrm{II}}(\mathrm{L})_{2} \cdot \mathbf{2} \mathrm{H}_{2} \mathrm{O}$ & $\begin{array}{l}\text { (1) } 329 \\
\text { (2) } 585\end{array}$ & $\begin{array}{l}\text { (1) } 10600 \\
\text { (2) } 890\end{array}$ & 569.4 & $\begin{array}{l}{\left[\mathrm{MnL}_{2}\right.} \\
\left.+2 \mathrm{H}^{+}\right]\end{array}$ & $\begin{array}{l}60.27 \\
(59.7)\end{array}$ & $\begin{array}{c}4.43 \\
(5.34)\end{array}$ & $\begin{array}{c}4.23 \\
(4.64)\end{array}$ & $\mathrm{C}_{30} \mathrm{H}_{32} \mathrm{~N}_{2} \mathrm{O}_{8} \mathrm{Mn}$ \\
\hline $\mathrm{VO}^{\mathrm{IV}}(\mathrm{L})_{2} \cdot 2 \mathrm{H}_{2} \mathrm{O}$ & $\begin{array}{l}\text { (1) } 269 \\
\text { (2) } 310 \\
\text { (3) } 430\end{array}$ & $\begin{array}{l}\text { (1) } 18600 \\
\text { (2) } 15830 \\
\text { (3) } 4560\end{array}$ & 580.7 & $\begin{array}{c}{\left[\mathrm{VOL}_{2}+\right.} \\
\left.\mathrm{H}^{+}\right]\end{array}$ & $\begin{array}{c}58.08 \\
(58.54)\end{array}$ & $\begin{array}{c}4.62 \\
(5.24)\end{array}$ & $\begin{array}{c}3.47 \\
(4.55)\end{array}$ & $\mathrm{C}_{30} \mathrm{H}_{32} \mathrm{~N}_{2} \mathrm{O}_{9} \mathrm{~V}$ \\
\hline
\end{tabular}

${ }^{\mathrm{a}}$ Wavelength of maximum absorbance; ${ }^{\mathrm{b}}$ Molar attenuation coefficient; ${ }^{\mathrm{c}}$ Some of the major fragmentation peaks observed on the mass spectra of nickel(II), manganese(II) and oxovanadium(IV) complexes; ${ }^{d}$ Measured C, H, N contents (atomic \%) in the complexes and the calculated ones (in brackets) from the proposed molecular formulae.

\subsection{Spectroscopic characterizations of the complexes}

\subsubsection{FT-IR Spectroscopy}

Figure 1 shows the FT-IR spectra of the synthesized complexes, whereas Table 2 collects the wavelength of some of the bands assigned to stretching and bending vibrations. The FT-IR spectra of all complexes (Fig. 1) display bands between 3650 and $3200 \mathrm{~cm}^{-1}$ due to $v(\mathrm{OH})$ of crystalline or coordinated water 
molecules associated with the complex. The absorption bands in the region 3000-2900 $\mathrm{cm}^{-1}$ may be due to aliphatic and aromatic $v(\mathrm{C}-\mathrm{H})$ [24], whereas the bands between 1050 and $1020 \mathrm{~cm}^{-1}$ may correspond to $v(\mathrm{C}-\mathrm{O}-\mathrm{C})$ stretching vibration of the methoxy group [23]. In addition, the complexes possessed a potential donor site, like the azomethine group $(-\mathrm{C}=\mathrm{N})$, which has tendency to coordinate with metal ions. The strong bands associated to this group are generally situated between 1660 and $1630 \mathrm{~cm}^{-1}$ [25]. Specifically, for the studied ligand this band was observed at $1644 \mathrm{~cm}^{-1}$ [5], but it is found shifted to lower frequencies by $6 \mathrm{~cm}^{-1}$ in the spectrum of the nickel complex, and shifted to higher frequencies by about $14 \mathrm{~cm}^{-1}$ in the spectra of the manganese and oxovanadium complexes. This result suggests that the azomethine nitrogen may be coordinated to the metallic centers. Additionally, the bands at $1247-1253 \mathrm{~cm}^{-1}$ are assigned to C$\mathrm{O}$ stretch of the phenolate group in the complexes. These bands undergo a displacement to the higher frequencies comparing with the value of this band in the corresponding ligand (at about $1240 \mathrm{~cm}^{-1}$ [5]) in compliance with deprotonation and coordination of the phenolate oxygen to the metal [26]. 


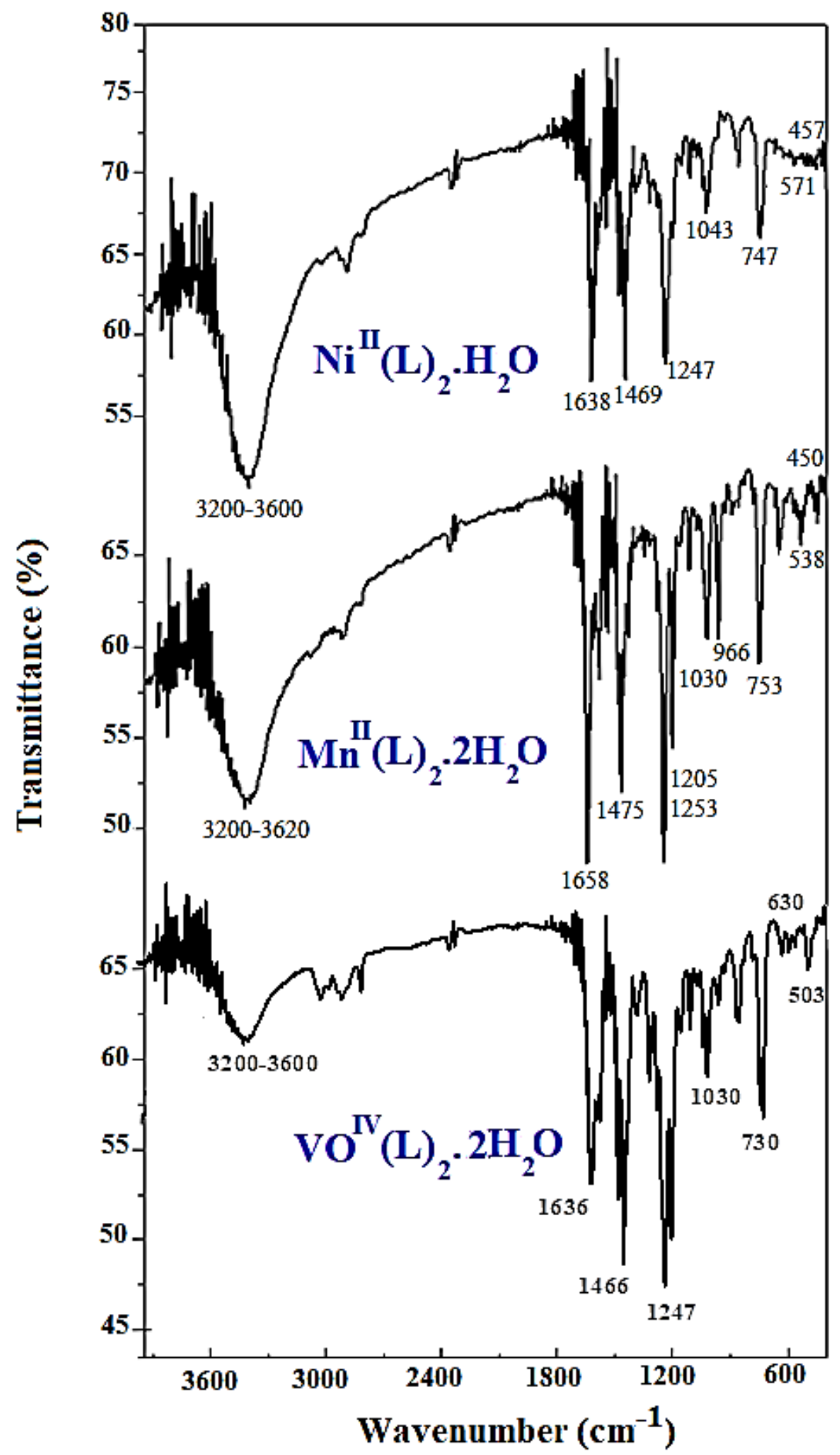

Fig.1. FT-IR Spectra of the obtained nickel(II), manganese(II) and oxovanadium(IV) complexes. 
Table 2. Characteristic FT-IR bands $\left(4000-400 \mathrm{~cm}^{-1}\right)$ of the synthesized complexes.

\begin{tabular}{cccccccccc}
\hline Complex & $\mathbf{v}(\mathbf{O}-\mathbf{H})$ & $\begin{array}{l}\mathbf{v}(\mathbf{C}-\mathrm{H}) \\
\text { (arom.) }\end{array}$ & $\begin{array}{l}\mathbf{v}(\mathbf{C}-\mathbf{H}) \\
\text { (aliph.) }\end{array}$ & $\mathbf{v}(\mathbf{C}=\mathbf{N})$ & $\mathbf{v}(\mathbf{C}-\mathbf{O})$ & $\mathbf{v}(\mathbf{C}-\mathbf{O}-\mathrm{C})$ & $\mathbf{v}(\mathbf{V}=\mathbf{O})$ & $\mathbf{v}(\mathbf{M}-\mathrm{O})$ & $\mathbf{v}(\mathbf{M}-\mathrm{N})$ \\
\hline Nickel & $3600-3200$ & 3077 & 2951 & 1638 & 1247 & 1043 & - & 552 & 445 \\
Manganese & $3620-3200$ & 3079 & 2945 & 1658 & 1253 & 1030 & - & 538 & 450 \\
Oxovanadium & $3650-3200$ & 3080 & 2950 & 1658 & 1253 & 1023 & 970 & 531 & 443 \\
\hline
\end{tabular}

In oxovanadium complexes, a strong band at $970 \mathrm{~cm}^{-1}$ was observed and can be assigned to $v(\mathrm{~V}=\mathrm{O})$ vibrations [27]. The coordination of the Schiff base ligands to the metal ions is also confirmed by the appearance of new bands in spectra of metal complexes in the range of $460-440 \mathrm{~cm}^{-1}$, which may be assigned to the $v(\mathrm{M}-\mathrm{N})$ bond [28]. Another absorption band was also seen, not far from the previous $v(\mathrm{M}-$ N) frequency, in the region of 560-530 $\mathrm{cm}^{-1}$ corresponding to $v(\mathrm{M}-\mathrm{O})$ bond [28]. Considering these results, it can be inferred that the two Schiff base molecules coordinating the metallic centers in the three complexes may act as dibasic bis-bidentate ligands.

\subsection{2. $U V$-Vis Spectroscopy}

Electronic (UV-Vis) spectra of all complexes have been recorded in DMF solvent $\left[10^{-4} \mathrm{M}\right]$ (Fig. 2). For all the complexes, an absorption band relatively intense was observed between 260 and $280 \mathrm{~nm}$. This band could be ascribed to the $\pi-\pi^{*}$ transitions of aromatic rings and azomethine groups. In the case of the electronic spectrum of nickel complex, another band at $380 \mathrm{~nm}$ was seen. This band is assigned to the ligand-metal charge-transfer (LMCT) transition $\mathrm{O}_{\text {phenolate }} \rightarrow \mathrm{Ni}(\mathrm{II})$.

As for the spectrum of manganese complex, two bands are observed. The first one located at $329 \mathrm{~nm}$ is characteristic of the charge-transfer (LMCT) transition $\mathrm{Mn}(\mathrm{III}) \rightarrow \mathrm{O}_{\text {phenolate, }}$ thus appearing shifted to higher energy when compared to the same band of nickel complex [29,30]. The second appears as a broad band centered at $585 \mathrm{~nm}$. This electronic transition is attributed to a charge-transfer (LMCT) between p $\pi$ orbital of the ligand and $\mathrm{d} \pi$-orbital of $\mathrm{Mn}(\mathrm{II})[31,32]$.

Regarding the spectrum of oxovanadium complex, it shows two types of transitions. The first absorption band at $310 \mathrm{~nm}$ corresponds to $\mathrm{n}-\pi^{*}$ transitions, while the second one at $430 \mathrm{~nm}$ may be also attributable to the charge-transfer (LMCT) transition from the phenolic oxygen ( $\left.\mathrm{O}_{\text {phenolate }}\right)$ to the empty $d$ orbital's on the vanadium $[33,34]$. 
Accordingly, upon coordination, these observed bands appear between 320-600 nm correspond to square planar geometry for $\mathrm{Ni}$ (II) complex [35], octahedral geometry for $\mathrm{Mn}$ (II) complex [36] and squarepyramidal geometry for VO(IV) complex [37].

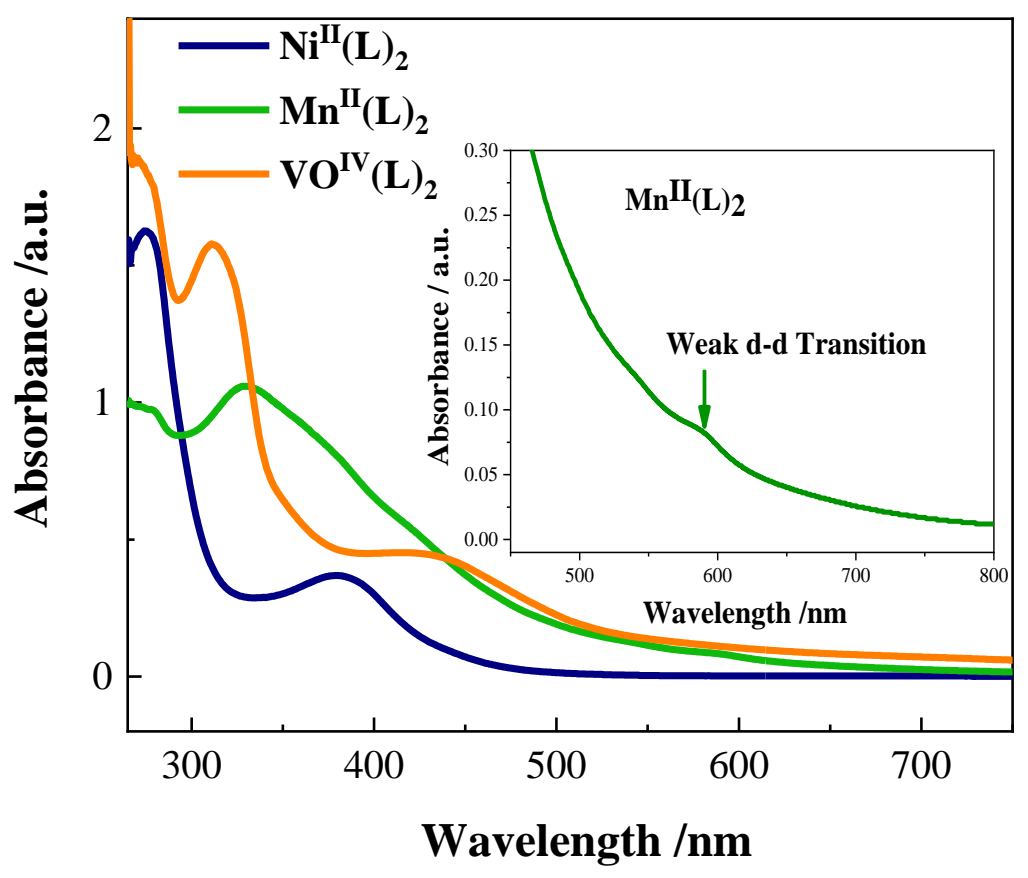

Fig.2. UV-Vis Spectra of the obtained nickel(II), manganese(II) and oxovanadium(IV) complexes.

\subsubsection{Mass spectrometry}

Mass spectrometry is potentially considered as a powerful structural characterization technique in molecular chemistry. This technique has also been successfully applied in coordination chemistry to elucidate the major molecular ion peaks of our synthesized Schiff base complexes. This analysis was carried out by HPLC chromatography coupled with mass spectrometry technique (LC-MS).

The mass spectrum of nickel complex (Fig. 3) displays a fragmentation ion peak with $\mathrm{m} / \mathrm{z}=571.1$, which may correspond to the parent molecular ion peak $\left[\mathrm{Ni}^{(\mathrm{II})} \mathrm{L}_{2}\right]^{+}$(calc. 571.2). On the other hand, a base peak with $\mathrm{m} / \mathrm{z}$ equal to 258.1 was observed. This could be assigned to the mass of ligand diprotonated [L+ $2 \mathrm{H}]^{+}$. The molecular structure deduced from these mass fragmentation patterns is included in the Scheme 2. 

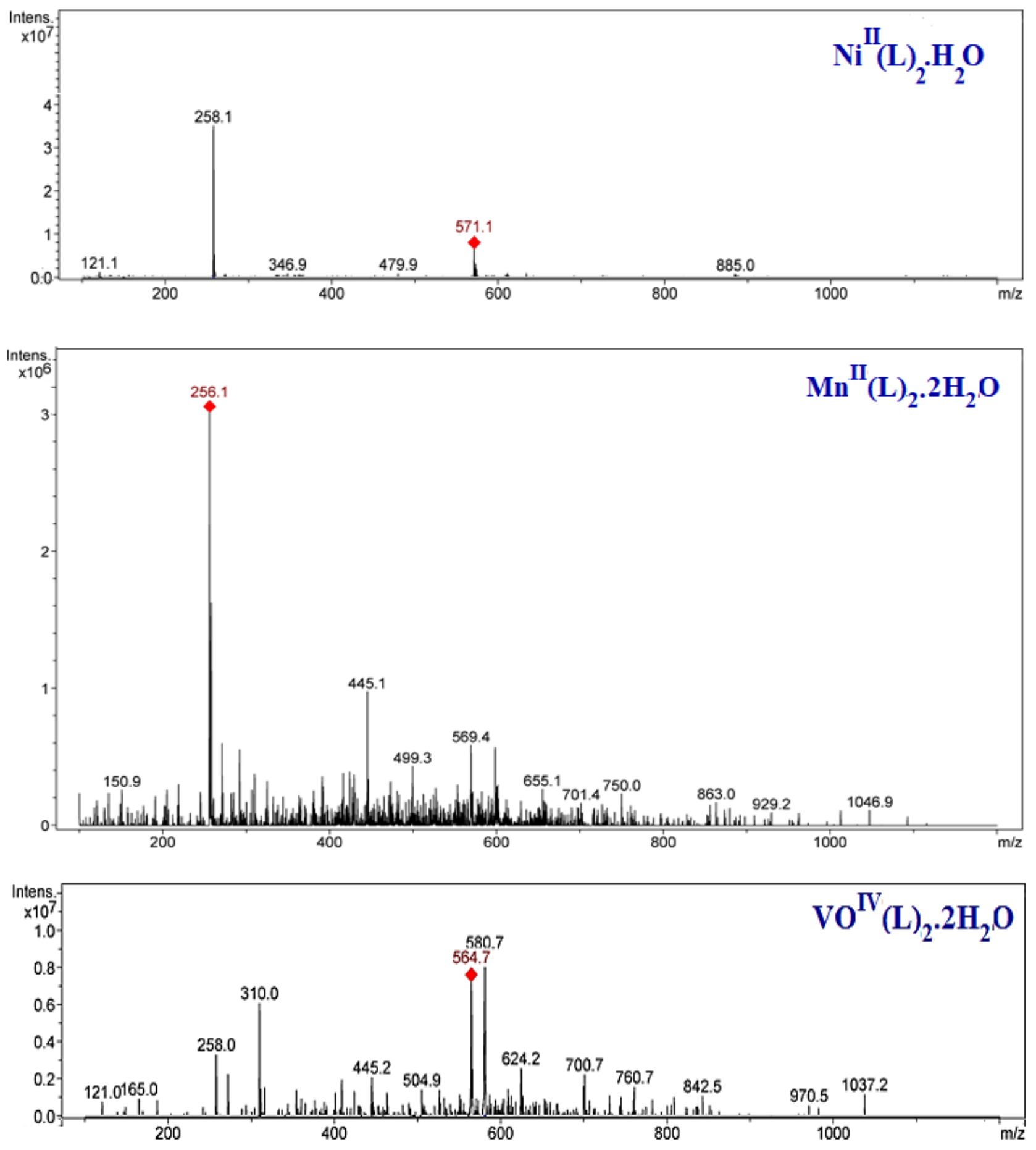

Fig. 3. Mass spectra of nickel(II), manganese(II) and oxovanadium(IV) complexes. 


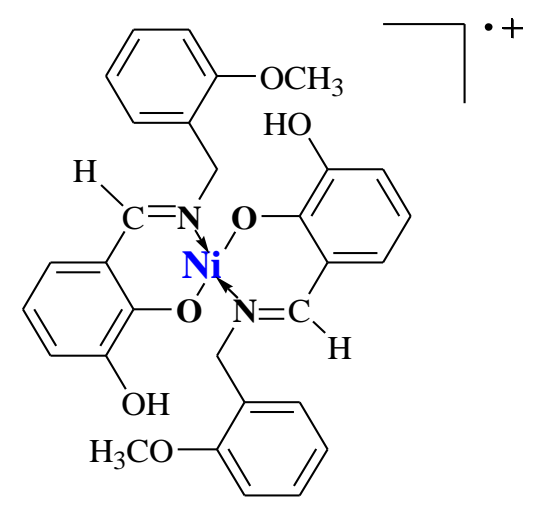

$(\mathrm{m} / \mathrm{z}=571.1,22 \%)$<smiles>CC[C+](C)CC</smiles>

$(\mathrm{m} / \mathrm{z}=258.1,100 \%)$

$$
\mathrm{Ni}^{\mathrm{II}}(\mathrm{L})_{2} \cdot \mathrm{H}_{2} \mathrm{O}
$$
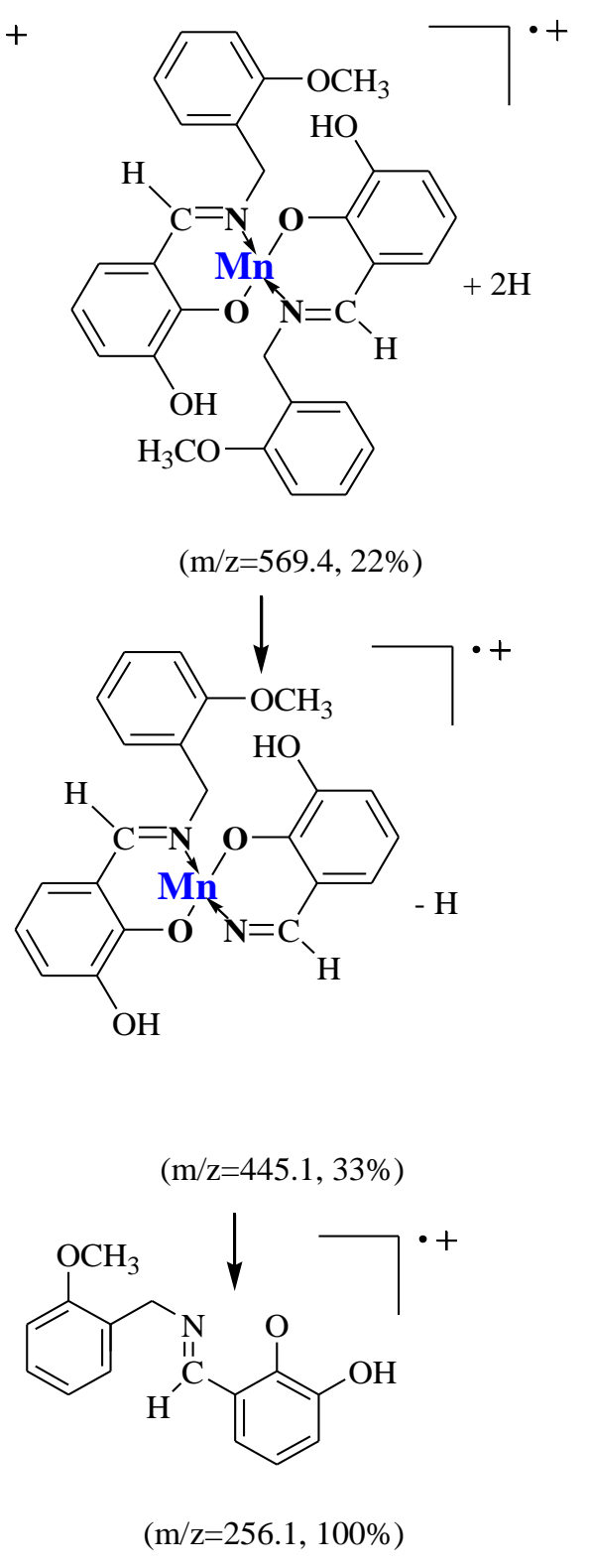

$$
\mathrm{Mn}^{\mathrm{II}}(\mathrm{L})_{2} \cdot \mathbf{2} \mathrm{H}_{2} \mathrm{O}
$$
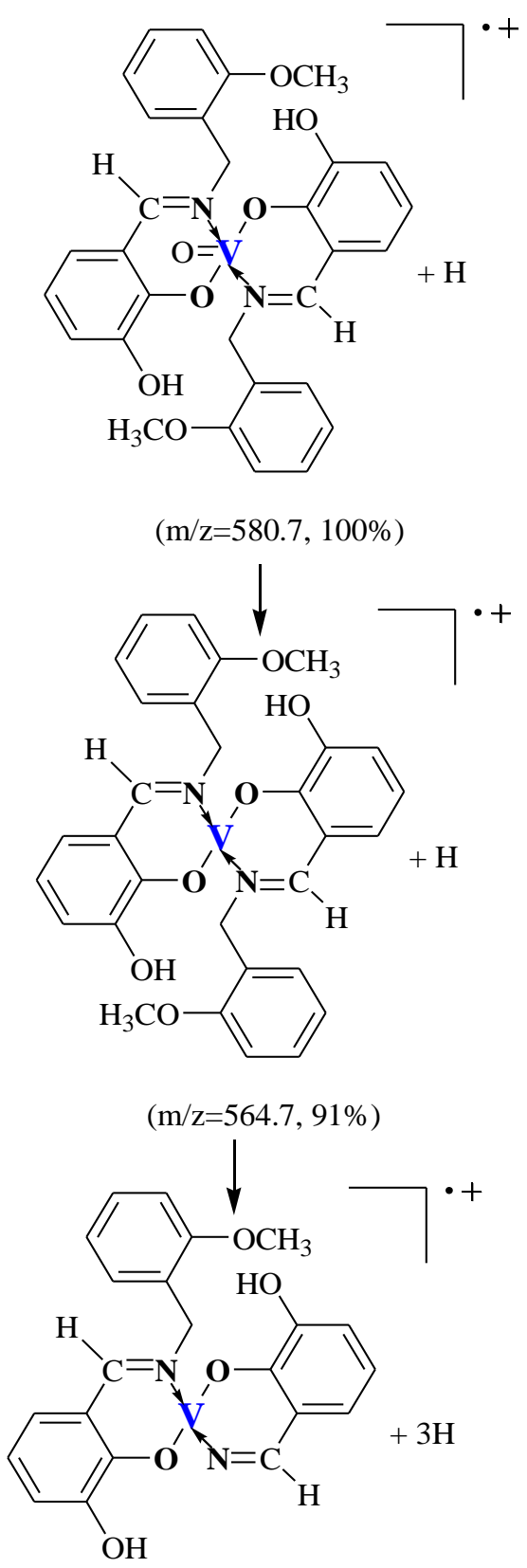

$(\mathrm{m} / \mathrm{z}=445.2,25 \%)$<smiles>COc1ccccc1CN=Cc1cccc(O)c1O</smiles>

$(\mathrm{m} / \mathrm{z}=258.0,41 \%)$

$\mathrm{VO}^{\mathrm{IV}}(\mathrm{L})_{2} \cdot \mathbf{2} \mathrm{H}_{2} \mathrm{O}$ 
Scheme 2. Proposed major fragment ions deduced from the mass spectra of nickel(II), manganese(II) and oxovanadium(IV) complexes.

As for the mass spectrum of the manganese complex, it shows a molecular ion peak with $\mathrm{m} / \mathrm{z}$ ratio equal to 569.4. This fragment ion may fit with the molecular weight of the expected compound. Moreover, another important fragment with $\mathrm{m} / \mathrm{z}$ ratio $=445.1(33.4 \%)$ is observed, which may correspond to the $\left[\mathrm{C}_{21} \mathrm{H}_{19} \mathrm{O}_{5} \mathrm{Mn}-\mathrm{H}\right]^{+}$ion (Scheme 2). The fragment with $\mathrm{m} / \mathrm{z}=256.1$, with a relative abundance of $100 \%$, is assigned to the ligand $[\mathrm{L}]^{+}$, what confirms its high stability and therefore corresponds to the base peak. For the last complex of oxovanadium, it exhibits a strong peak at $\mathrm{m} / \mathrm{z}=580.7$ (100\%), which may be indicative of the molecular peak and also the base peak. This behavior seems to be the main particularity for this compound when compared to the previous complexes of $\mathrm{Ni}(\mathrm{II})$ and $\mathrm{Mn}$ (II). In addition, the mass spectrum shows again multiple peaks representing successive degradation of this complex leading to the formation of different fragments (Scheme 2), highlighting among them the Schiff base ligand ion peak[L] ${ }^{+}$ of $\mathrm{m} / \mathrm{z}=258.0(41.0 \%)$.

All these results confirmed that the synthesized complexes are mononuclear, with two molecular moieties of Schiff base ligands, and they are, therefore, in good agreement with their molecular structure proposed in the Scheme 1.

\subsection{Thermogravimetric analysis (TG/DTG)}

Figure 4 shows the TG and DTG curves recorded for the three metal complexes. As it is observed, upon increasing the temperature, the complexes showed a gradual weight loss. Generally, this weight loss can be initially assigned to the release of water molecules, followed by other successive decompositions leading to the formation of metallic oxides. Particularly, the different decomposition stages, temperature ranges, DTG peak positions, as well as the experimental and calculated mass loss percentages for these complexes are summarized in Table 3.

First, the thermogram of nickel complex undergoes decomposition in four steps (Fig. 4A). The first one is accompanied by a weight loss of $3.8 \%$, which may correspond to the release of one molecule of water (theoretically calculated $=3.05 \% \%$ ). The DTG curve of the second step, for which the temperatures ranged from 220 to $300{ }^{\circ} \mathrm{C}$, clearly indicates a weight loss centered at $242{ }^{\circ} \mathrm{C}$ of $17.7 \%$. This decomposition process is attributed to the removal of the methoxyphenyl moiety (theoretically calculated $=18.15 \%$ ). With a weight loss of $13.0 \%$, the third decomposition step seems to represent the loss of 
phenyl moiety (theoretically calculated $=12.89 \%$ ). Regarding the last process evidenced at $557.4{ }^{\circ} \mathrm{C}$ on the DTG curve $\left(24.2 \%\right.$ loss), it seems to be due to the removal of the organic entity $\left(\mathrm{C}_{3} \mathrm{H}_{17} \mathrm{~N}_{2} \mathrm{O}_{4}\right)$ (theoretically calculated $=24.6 \%$ ). Finally, the remaining final residue is identified as $\mathrm{NiO}$ with 16 carbon [38].

For the manganese complex (Fig. 4B), the first decomposition ranges between 138.6-222.5 ${ }^{\circ} \mathrm{C}$ and it involves a weight loss of $3.0 \%$, so it is attributed to the removal of one molecule of water (theoretically calculated $=2.98 \%$ ). The second step between 144.7 and $350{ }^{\circ} \mathrm{C}$ shows a weight loss of $12.6 \%$, thus, being explained by the removal of one molecule of water and two methoxy $\left(-\mathrm{OCH}_{3}\right)$ moieties from the ligand (theoretically calculated $=13.25 \%$ ). The next step observed in the temperature range from 326 to $442{ }^{\circ} \mathrm{C}$ implies a weight loss of $20 \%$, probably representing the decomposition of the $\mathrm{C}_{8} \mathrm{H}_{7} \mathrm{~N}$ part (theoretically calculated $=19.38 \%)$. As for the last step occurring in the range of $451-947{ }^{\circ} \mathrm{C}(22.6 \%$ weight loss), it may account for the loss of the remaining organic part $\left(\mathrm{C}_{5} \mathrm{H}_{15} \mathrm{NO}_{3}\right)$. These four stages were denoted by the DTG peaks at about 181.6, 343.4, 375.1 and 578.9, respectively. The final residue may be manganese oxide $(\mathrm{MnO})$, with carbon atoms (15C) [39].

Finally, the thermal decomposition of the vanadium complex (Fig. 4C) displays also four decomposition steps in the temperature ranges of 50.5-91.8, 190-250, 269.5-438.9 and 452.4-528.9 ${ }^{\circ} \mathrm{C}$ and DTG peaks at $70.7,222.3,382.6$ and $491.0^{\circ} \mathrm{C}$, respectively. With a weight loss of $5.5 \%$, the first one corresponds to the loss of two water molecules, as previously mentioned for the manganese complex. The second step with a weight loss of $12.7 \%$ indicates also the loss of the phenyl group (theoretically calculated $=12.34$ $\%)$. Because these processes are also observed for nickel and manganese complexes, the obtained results suggest the existence of a similarity in the thermal decomposition pathway of the complexes. However, the last decomposition step of the vanadium complex leaving $41.5 \%$ residue as $\mathrm{VO}_{2}$ and $14 \mathrm{C}$ [40]. 

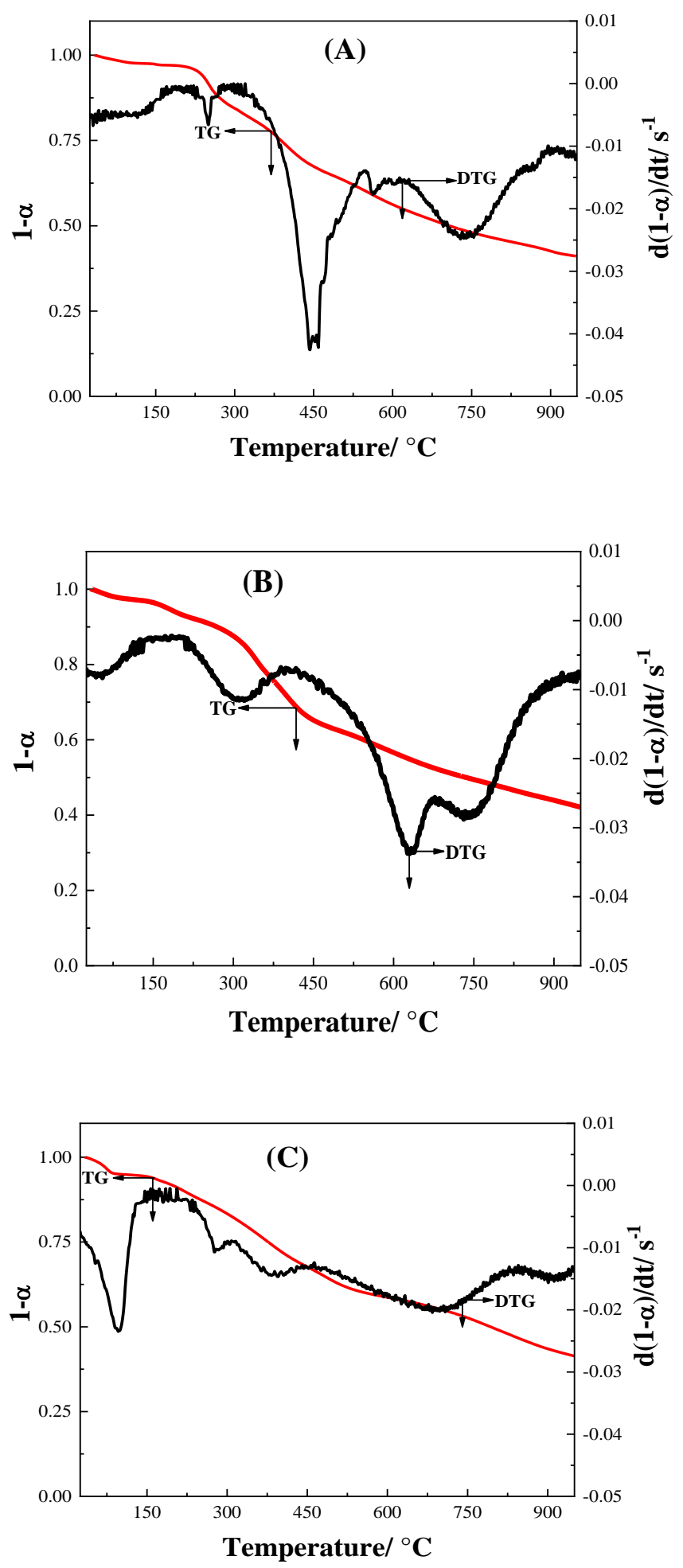

Fig. 4. The TG and DTG of (A)- Ni(II), (B)- Mn(II) and (C)- VO(IV) Schiff base complexes (where $\alpha$, is the conversion $=1-\mathrm{w} / \mathrm{w}_{0}, \mathrm{w}=$ the residual weight in $\mathrm{mg}$ and $\mathrm{w}_{0}$ is the initial weight of the sample in $\mathrm{mg}$ ). Table 3. Thermal decomposition data for the prepared complexes. 


\begin{tabular}{|c|c|c|c|c|c|c|}
\hline Samples & $\begin{array}{l}\text { Number } \\
\text { of steps }\end{array}$ & $\begin{array}{c}\text { Temp. range } \\
\quad /{ }^{\circ} \mathrm{C}\end{array}$ & $\begin{array}{c}\mathbf{T}_{\max } / \\
{ }^{\circ} \mathbf{C}\end{array}$ & $\begin{array}{c}\text { Mass loss /\% } \\
\text { Found } \\
\text { (Calcd.) }\end{array}$ & Assignments & $\begin{array}{c}\text { Residue/\% } \\
\text { Found } \\
\text { (Calcd.) }\end{array}$ \\
\hline $\mathrm{Ni}^{\mathrm{II}}(\mathrm{L})_{2} \cdot \mathrm{H}_{2} \mathrm{O}$ & 4 & $\begin{array}{l}125.9-173.4 \\
220.6-300.0 \\
337.9-450.3 \\
522.6-613.6\end{array}$ & $\begin{array}{l}144.6 \\
242.0 \\
396.8 \\
557.4\end{array}$ & $\begin{array}{c}3.8(3.05) \\
17.7(18.15) \\
13.0(12.89) \\
24.2(24.6)\end{array}$ & $\begin{array}{l}\text { Loss of } \mathrm{H}_{2} \mathrm{O} \\
\text { Loss of } \mathrm{C}_{7} \mathrm{H}_{7} \mathrm{O} \\
\text { Loss of } \mathrm{C}_{6} \mathrm{H}_{4} \\
\text { Loss of } \mathrm{C}_{3} \mathrm{H}_{17} \mathrm{~N}_{2} \mathrm{O}_{4}\end{array}$ & $\begin{array}{c}41.3(41.41) \\
\mathrm{NiO}+16 \mathrm{C}\end{array}$ \\
\hline $\mathrm{Mn}^{\mathrm{II}}(\mathrm{L})_{2} \cdot 2 \mathrm{H}_{2} \mathrm{O}$ & 4 & $\begin{array}{l}138.6-222.5 \\
144.7-350.0 \\
326.7-442.0 \\
451.0-947.0\end{array}$ & $\begin{array}{l}181.6 \\
343.4 \\
375.1 \\
578.0\end{array}$ & $\begin{array}{c}3.0(2.98) \\
12.6(13.25) \\
20(19.38) \\
22.6(22.7)\end{array}$ & $\begin{array}{l}\text { Loss of } \mathrm{H}_{2} \mathrm{O} \\
\text { Loss of } \mathrm{H}_{2} \mathrm{O}+2\left(\mathrm{CH}_{3} \mathrm{O}\right) \\
\text { Loss of } \mathrm{C}_{8} \mathrm{H}_{7} \mathrm{~N} \\
\text { Loss of } \mathrm{C}_{5} \mathrm{H}_{15} \mathrm{NO}_{3}\end{array}$ & $\begin{array}{l}41.8(41.69) \\
\mathrm{MnO}+15 \mathrm{C}\end{array}$ \\
\hline $\mathrm{V}^{\mathrm{IV}} \mathrm{O}(\mathrm{L})_{2} \cdot 2 \mathrm{H}_{2} \mathrm{O}$ & 4 & $\begin{array}{c}50.5-91.8 \\
190.0-250.0 \\
269.5-438.9 \\
452.4-528.9\end{array}$ & $\begin{array}{c}70.7 \\
222.3 \\
382.6 \\
491.0\end{array}$ & $\begin{array}{c}5.5(5.84) \\
12.7(12.34) \\
21.6(21.93) \\
18.7(19.01)\end{array}$ & $\begin{array}{l}\text { Loss of } 2 \mathrm{H}_{2} \mathrm{O} \\
\text { Loss of } \mathrm{C}_{6} \mathrm{H}_{4} \\
\text { Loss of } \mathrm{C}_{8} \mathrm{H}_{9} \mathrm{NO} \\
\text { Loss of } \mathrm{C}_{2} \mathrm{H}_{15} \mathrm{NO} 4\end{array}$ & $\begin{array}{l}41.5(40.79) \\
\mathrm{VO}_{2}+14 \mathrm{C}\end{array}$ \\
\hline
\end{tabular}

\subsection{Electrochemical behavior}

Cyclic voltammetry measurements were carried out to investigate the redox properties of the complexes in solution. Figure 5 displays the voltammetric curves of the nickel complex in the potential range from +1.6 to $-2.2 \mathrm{~V}$ and the manganese complex between +1.4 to $-1.4 \mathrm{~V}$. 

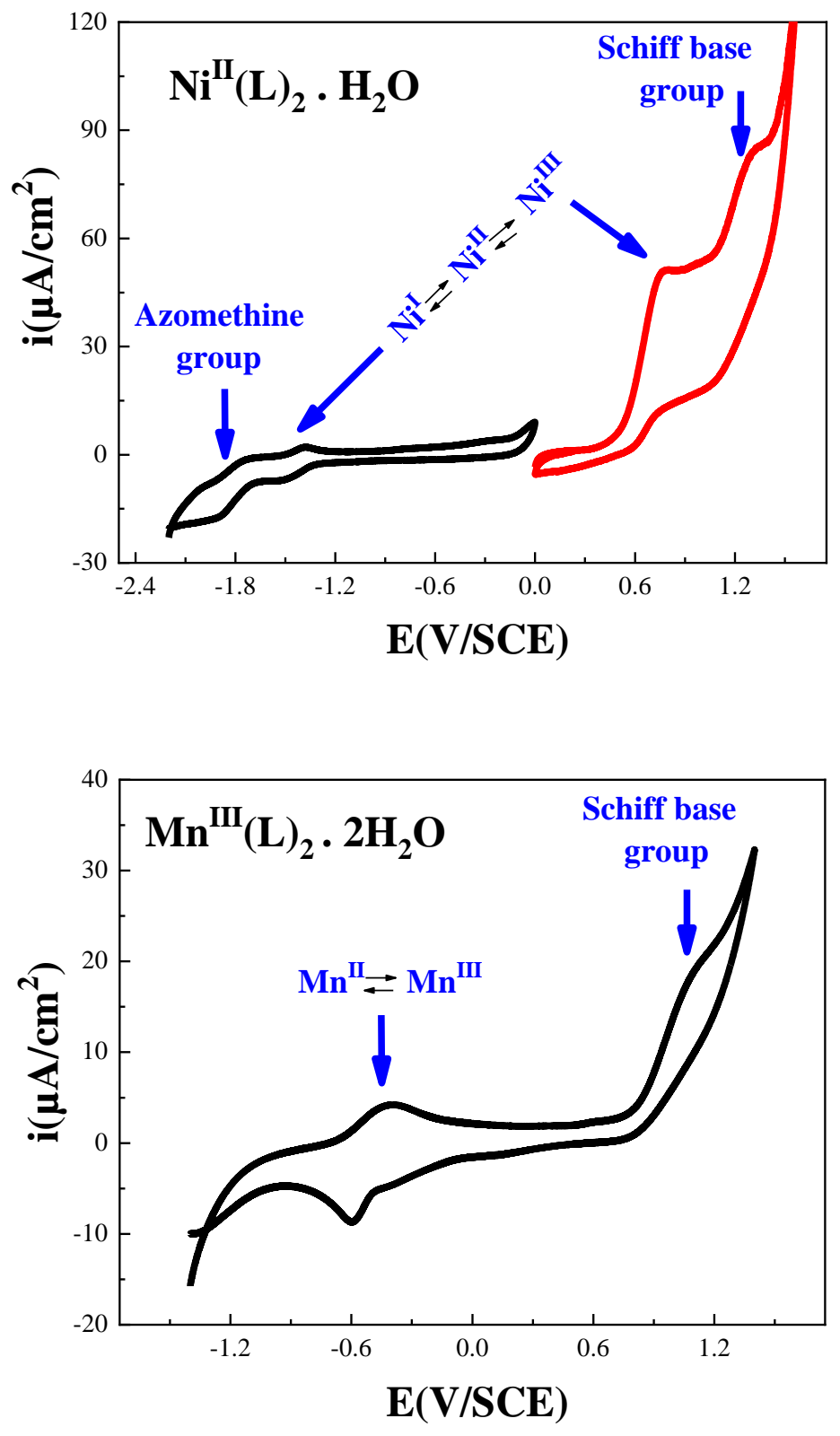


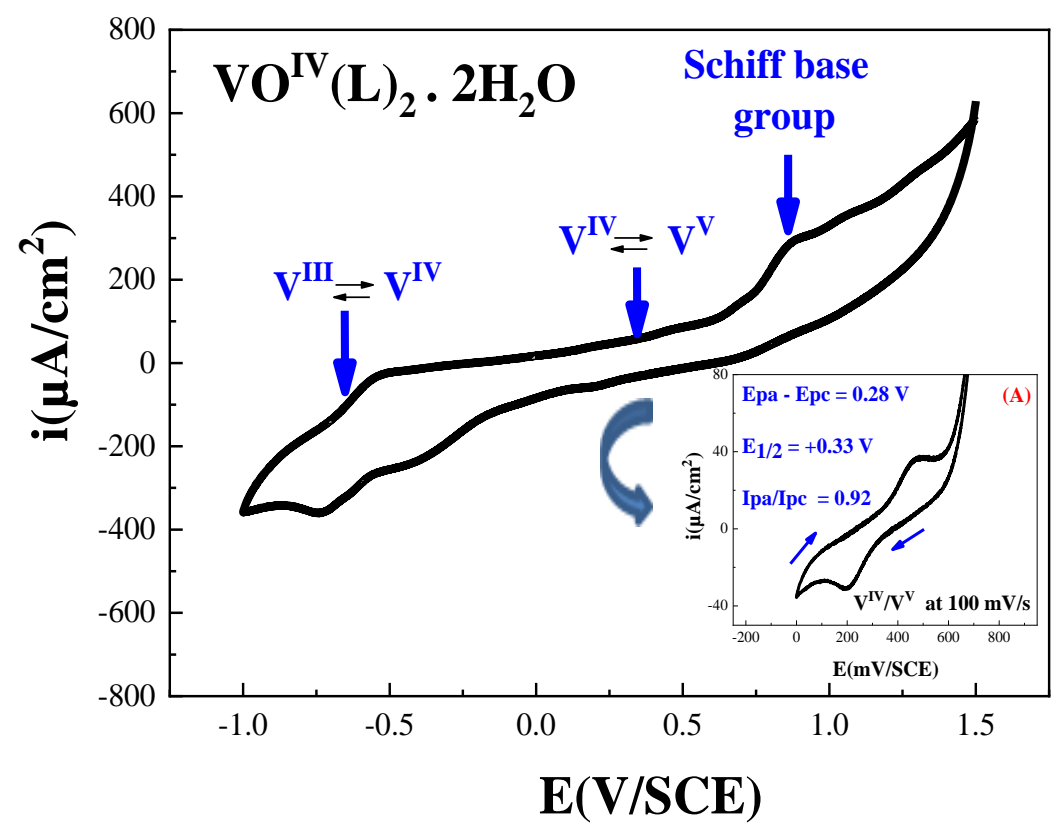

Fig. 5. Cyclic voltammograms of a GC electrode in a solution containing $10^{-3} \mathrm{M}$ nickel (A), manganese (B) or oxovanadium $(\mathbf{C})$ complexes and $0.1 \mathrm{M}$ of $\mathrm{TBABF}_{4}$ in DMSO, under argon atmosphere, at a scan rate of $100 \mathrm{mV} / \mathrm{s}$.

In the case of the nickel complex (see Fig. 5A), the voltammogram displays four redox processes. When the electrode potential is scanned towards negative values, a reduction peak is observed at $-1.53 \mathrm{~V}$, and its corresponding oxidation pair appears in the reverse scan at $-1.38 \mathrm{~V}(\Delta \mathrm{E}=\mathrm{Epa}-\mathrm{Epc}=150 \mathrm{mV})$. The anodic to cathodic peak current density ratio (Ipa/Ipc) of this process is close to 1 , which is assigned to the metal centered $\mathrm{Ni}^{\mathrm{II}} / \mathrm{Ni}^{\mathrm{I}}$ redox couple $[\mathbf{4 1}, \mathbf{4 2}]$. Next, the reduction at $-1.91 \mathrm{~V}$, with a small oxidation counterpart $-1.71 \mathrm{~V}$ can be attributed to the irreversible reduction of azomethine group. When the electrode potential is scanned from 0.0 to $+1.60 \mathrm{~V}$, the complex exhibits a large oxidation current from ca. $+0.5 \mathrm{~V}$. A reduction couple is discerned in the reverse scan, so the process is characterized by an $\mathrm{E}_{1 / 2}=+0.65 \mathrm{~V}$ and peak separation about $\Delta \mathrm{E}=180 \mathrm{mV}$, and can be assigned to the $\mathrm{Ni}^{\mathrm{II}} / \mathrm{Ni}^{\mathrm{II}}$ redox couple [43]. Finally, an oxidation process is clearly observed at $+1.34 \mathrm{~V}$, which could probably be assigned to an oxidation of Schiff-base ligand [44].

The cyclic voltammogram of manganese complex (Fig. 5B) exhibits only one quasi-reversible redox couple with an anodic-cathodic peak separation $(\Delta \mathrm{E})$ equal to $200 \mathrm{mV}$. Its half wave potential value was 
then calculated as average of the anodic and cathodic peak potentials, which is found to be equal to $E_{1 / 2}=$ $-0.49 \mathrm{~V}$. These results suggest that this redox process may be described to $\mathrm{Mn}^{\mathrm{III}} / \mathrm{Mn}^{\mathrm{II}}$ [45]. On the other hand, the wave at Epa $=+1.12 \mathrm{~V}$ may probably correspond to the Schiff base ligand oxidation [44].

Cyclic voltammetry of the $\mathbf{V}^{\mathrm{IV}} \mathrm{O}(\mathbf{L})_{2} \cdot \mathbf{2} \mathrm{H}_{2} \mathrm{O}$ complex (see Fig. 5C) was performed in the potential range of -1.0 to $1.5 \mathrm{~V}$ vs. SCE. This voltammogram displays two redox processes. The reduction peak for the first redox couple is observed at $-0.74 \mathrm{~V}$, whereas its corresponding oxidation pair appears in the reverse scan at $-0.53 \mathrm{~V}$, being the peak to peak separation $\Delta \mathrm{E}=210 \mathrm{mV}$. According to literature, this redox process may be ascribed to $\mathrm{V}^{\mathrm{II}} / \mathrm{V}^{\mathrm{IV}}[\mathbf{4 6}]$. For the second couple (see a magnified voltammogram in the inset of Fig. 5C) the cathodic peak is centered at $\mathrm{Epc}=+0.2 \mathrm{~V}$ vs. SCE, and the anodic one at $\mathrm{Epa}=+0.48 \mathrm{~V}$ vs. SCE. This process has been attributed to the $\mathrm{V}^{\mathrm{IV}} / \mathrm{V}^{\mathrm{V}}$ redox couple [47] and it is characterized by $\Delta \mathrm{E}=$ $0.28 \mathrm{~V}$, Ipa/Ipc close to $1(0.92)$ and $\mathrm{E}_{1 / 2}=+0.33 \mathrm{~V}$. These two redox systems of the vanadium complex are proposed to be monoelectronic. The last oxidation wave observed at Epa $=+0.82 \mathrm{~V}$ may probably correspond to the Schiff base ligand oxidation [44].

\subsubsection{Effect of scan rate on the response of the $\mathrm{Ni}(\mathrm{II})$ complex}

The cyclic voltammogram of the nickel complex in DMSO solution under the potential range from- 0.8 to $-1.7 \mathrm{~V}$ shows a well-defined redox system (Fig. 6A) associated to $\mathrm{Ni}(\mathrm{II}) / \mathrm{Ni}(\mathrm{I})$. Specifically, the Epa is equal $-1.33 \mathrm{~V}$ and the cathodic peak is centered at $-1.47 \mathrm{~V}$, so this redox couple shows a peak separation $(\Delta \mathrm{E})$ equal to $130 \mathrm{mV}$, and the Ipc/Ipa (1.01) is practically equal to unity, suggesting an electrochemical process with one electron.
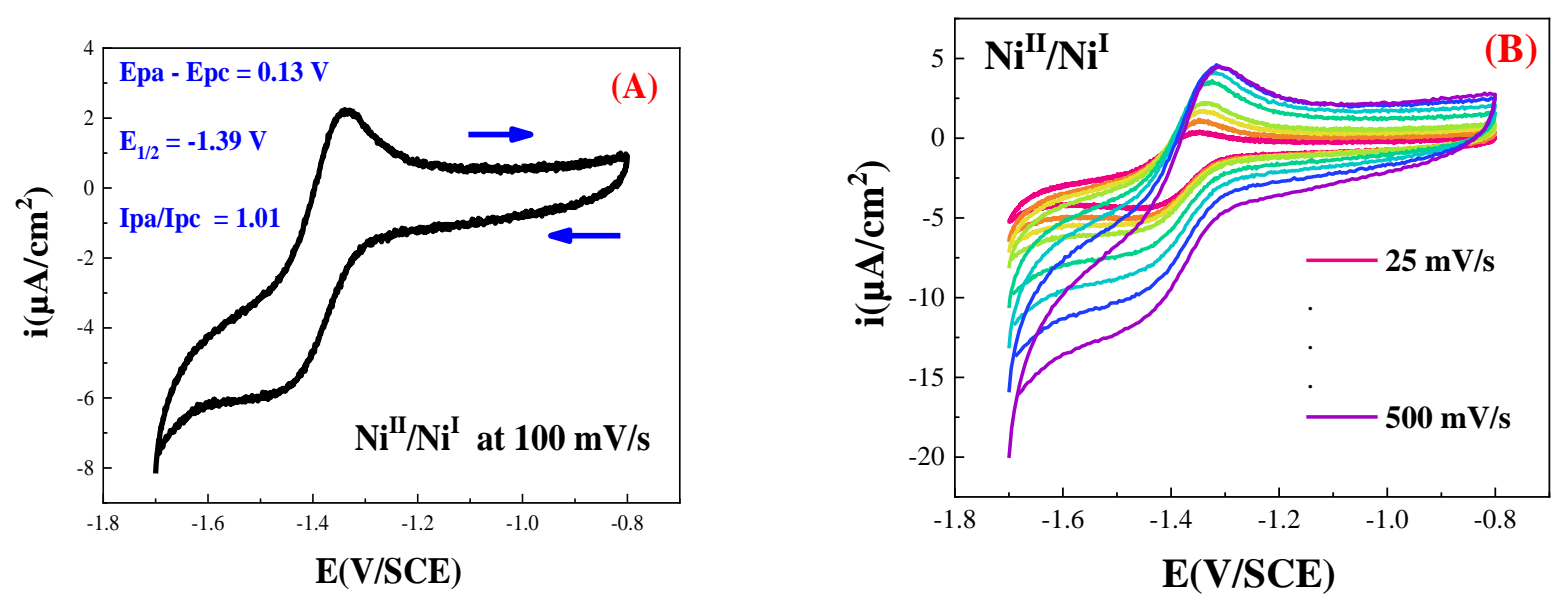

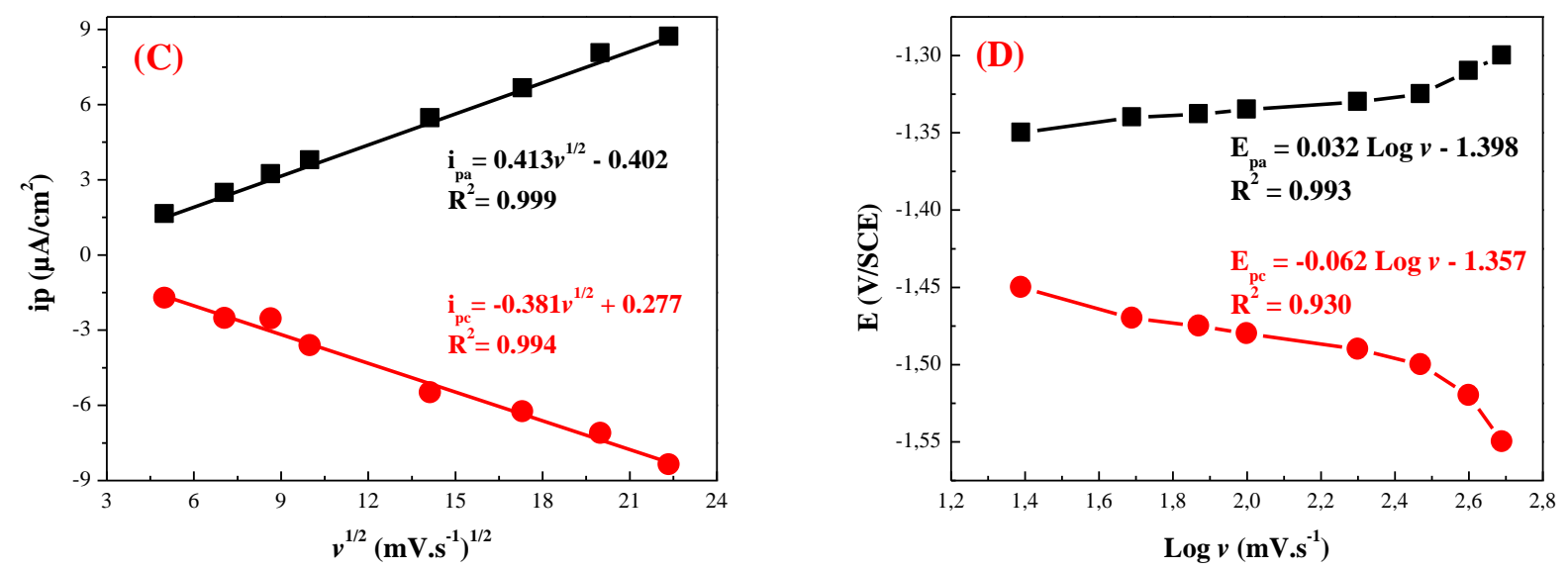

Fig. 6. (A) Cyclic voltammogram of the synthesized Ni(II) complex $\left(10^{-3} \mathrm{M}\right)$ in $0.1 \mathrm{M}$ TBABF$/ \mathrm{DMSO}$ at a scan rate of $100 \mathrm{mV} \mathrm{s}^{-1}$; (B) Cyclic voltammograms of the same complex at different scan rates; (C) Plot of the cathodic and anodic peak currents versus the square root of sweep rate $\left(\mathrm{v}^{1 / 2}\right)$ and (D) Anodic and cathodic potentials versus $\log v$.

The reversibility of the $\mathrm{Ni}(\mathrm{II}) / \mathrm{Ni}(\mathrm{I})$ redox process in the synthesized nickel complex was studied by cyclic voltammetry at different scan rates. Fig. 6B depicts the voltammograms of the complex varying the scan rate between 25 to $500 \mathrm{mV} \mathrm{s}^{-1}$. As it can be observed in the figure, the reversibility of the redox couple is well maintained even up to $500 \mathrm{mV} \mathrm{s}^{-1}$. The effect of the scan rate on the electrochemical parameters associated to this redox couple is summarized in the Table 4, whereas Figures 6C and 6D plot the cathodic and anodic peak current densities versus the square root of the scan rate $\left(v^{1 / 2}\right)$ and the corresponding peak potentials versus the logarithm of the scan rate $(\log v)$, respectively. The obtained results reveal a linear relationship between the peak current densities and $v^{1 / 2}$ (Fig. 6C). In addition, the anodic and cathodic peak potentials $(E p a, E p c)$ are found proportional to $\log v($ Fig. 6D). These behaviors are indicative of a diffusion-controlled electron transfer process [48].

Table 4. Electrochemical parameters obtained from cyclic voltammograms of Figure 6.

\begin{tabular}{|c|c|c|c|c|c|c|c|c|}
\hline $\mathbf{I P a} / \mathbf{I P c}$ & $\mathbf{0 . 9 5}$ & $\mathbf{0 . 9 7}$ & $\mathbf{1 . 0 2}$ & $\mathbf{1 . 0 1}$ & $\mathbf{1 . 0 2}$ & $\mathbf{1 . 0 3}$ & $\mathbf{1 . 0 1}$ & $\mathbf{1 . 0 1}$ \\
\hline $\boldsymbol{\Delta E} \mathbf{( m V )}$ & 100 & 130 & 137 & 140 & 160 & 180 & 210 & 220 \\
\hline $\mathbf{E}_{\mathbf{1} / \mathbf{2}} \mathbf{( m V )}$ & -1400 & -1405 & -1407 & -1410 & -1415 & -1418 & -1422 & -1425 \\
\hline
\end{tabular}




\section{DFT calculations for the ligand and complex structures}

\subsection{Geometry optimization}

The geometry of the HL ligand structure was optimized to investigate the geometric and electronic characteristics that may control its electron-donation character and, therefore, its reactivity. Calculations showed that the molecule is planar and two donating groups (one hydroxyl and one imino groups) are facing each other around the central point of the molecule Figure 7. The structure was found to be stabilized through hydrogen bonding formed between the hydroxyl and imino groups. This specific orientation suggested that the ligand could be bound to the metal ions in one plane, giving rise to the formation of a square planar geometry around the central metal ion $\mathrm{Ni}(\mathrm{II})$, while square-pyramidal and octahedral geometry around the central metal ion VO(IV) and Mn(II) complexes, respectively. The planar geometry was associated with symmetrical charge distribution among atoms. As can be observed from Fig. 7, Table $\mathbf{5}$, the calculated atomic charges indicate that the most negative atoms are the oxygen and nitrogen, whereas the attached protons are the most positive ones. Again, this charge distribution supports the idea that the HL molecule donates the electrons through these two groups. The orbital occupation of the highest occupied molecular orbital (HOMO) and the lowest unoccupied molecular orbital (LUMO) showed that electrons are delocalized through the whole molecule with calculated energy gap of $4.75 \mathrm{eV}$. 

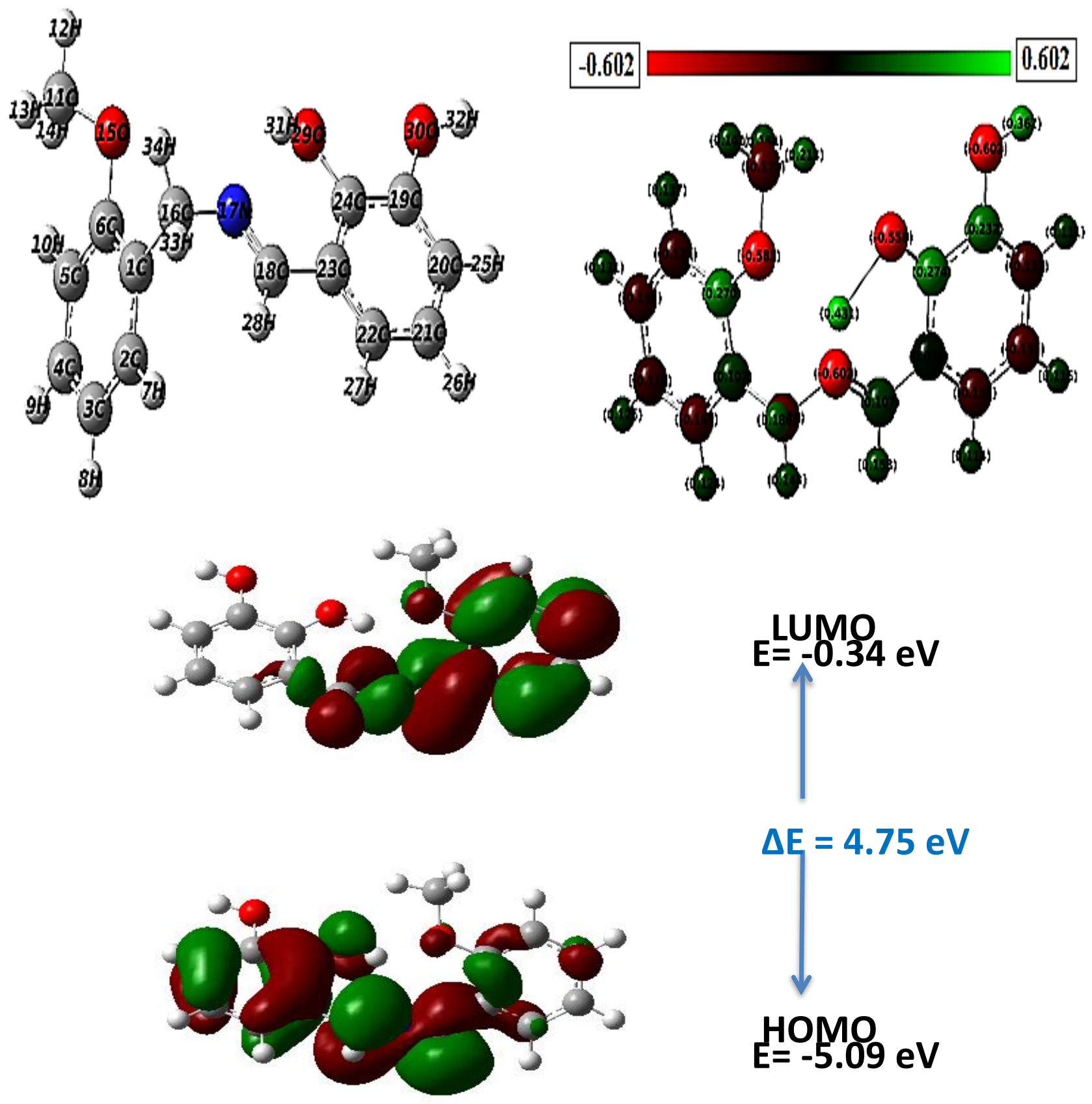

Figure 7. Proposed structures for the HL ligand, showing (A) the atomic charges distributions in color range and (B) the HOMO-LUMO orbitals occupation with the calculated energy gap, as optimized by DFT calculations. 
Table 5. Mulliken atomic charges calculated by B3LYP/6-31G(d,p) of the Schiff base ligand HL shown in Figure 7.

\begin{tabular}{|c|c|}
\hline Atom & Charge \\
\hline C1 & 0.102252 \\
\hline C2 & -0.164758 \\
\hline C3 & -0.118200 \\
\hline C4 & -0.135242 \\
\hline C5 & -0.121028 \\
\hline C6 & 0.269684 \\
\hline H7 & 0.124027 \\
\hline H8 & 0.126045 \\
\hline H9 & 0.130537 \\
\hline H10 & 0.137220 \\
\hline C11 & -0.173253 \\
\hline H12 & 0.213199 \\
\hline H13 & 0.141580 \\
\hline H14 & 0.153624 \\
\hline O15 & -0.582906 \\
\hline C16 & -0.176495 \\
\hline N17 & -0.602434 \\
\hline C18 & 0.107245 \\
\hline C19 & 0.231670 \\
\hline C20 & -0.131431 \\
\hline C21 & -0.157441 \\
\hline C22 & -0.139031 \\
\hline C23 & 0.029718 \\
\hline C24 & 0.273646 \\
\hline H25 & 0.110588 \\
\hline H26 & 0.116375 \\
\hline H27 & 0.114311 \\
\hline H28 & 0.157677 \\
\hline O29 & -0.558180 \\
\hline O30 & -0.601743 \\
\hline H31 & 0.430699 \\
\hline H33 & 0.361764 \\
\hline H34 & 0.144206 \\
\hline & 0.186075 \\
\hline
\end{tabular}


With respect to the calculations for the different complexes, the obtained results show that:

$>$ When optimizing $\mathrm{Ni}^{2+}$ ion complex with HL Schiff base ligand, the lowest energy structure has a square planar geometry with molecular formula $\left[\mathbf{N i}^{\mathbf{I I}}(\mathbf{L})_{2} \cdot \mathbf{H}_{2} \mathbf{O}\right]$. This geometry is accomplished with the protonation of the hydroxyl groups to neutralize the $\mathrm{Ni}^{2+}$ ion. The stability of this complex came from the formation of two four membered rings between $\mathrm{Ni}^{2+}$ and the ligand (Fig. 8a).

$>\mathrm{VO}^{2+}$ ion may form a square-pyramidal $\left[\mathbf{V}^{\mathbf{I V}} \mathbf{O}(\mathbf{L})_{2} \cdot \mathbf{2} \mathbf{H}_{2} \mathrm{O}\right]$ complex with the HL Schiff base ligand (Fig. 8b), where the ligand's donor groups coordinate in one plane with the metal ion. According to the lower energy of this conformation, the protons may rotate in opposite directions to prevent the steric interaction between the $\mathrm{VO}^{2+}$ and hydroxyl groups of $\mathbf{H L}$ (Fig. 8b).

$>$ the optimized structure of the $\mathrm{Mn}^{2+}$ complex may be octahedral. To attain this conformation the results suggest that, upon coordination, the ligand is deprotonated and that the octahedral geometry is fulfilled by two water molecules coordinated in a plane perpendicular to the Mn-HL plane (Fig. 8c). As a result, the donor groups of the ligand may be coordinated with the Mn(II) center in one plane.

All these (theoretical) results well agree with the molecular structures deduced from the analytical (experimental) techniques. 

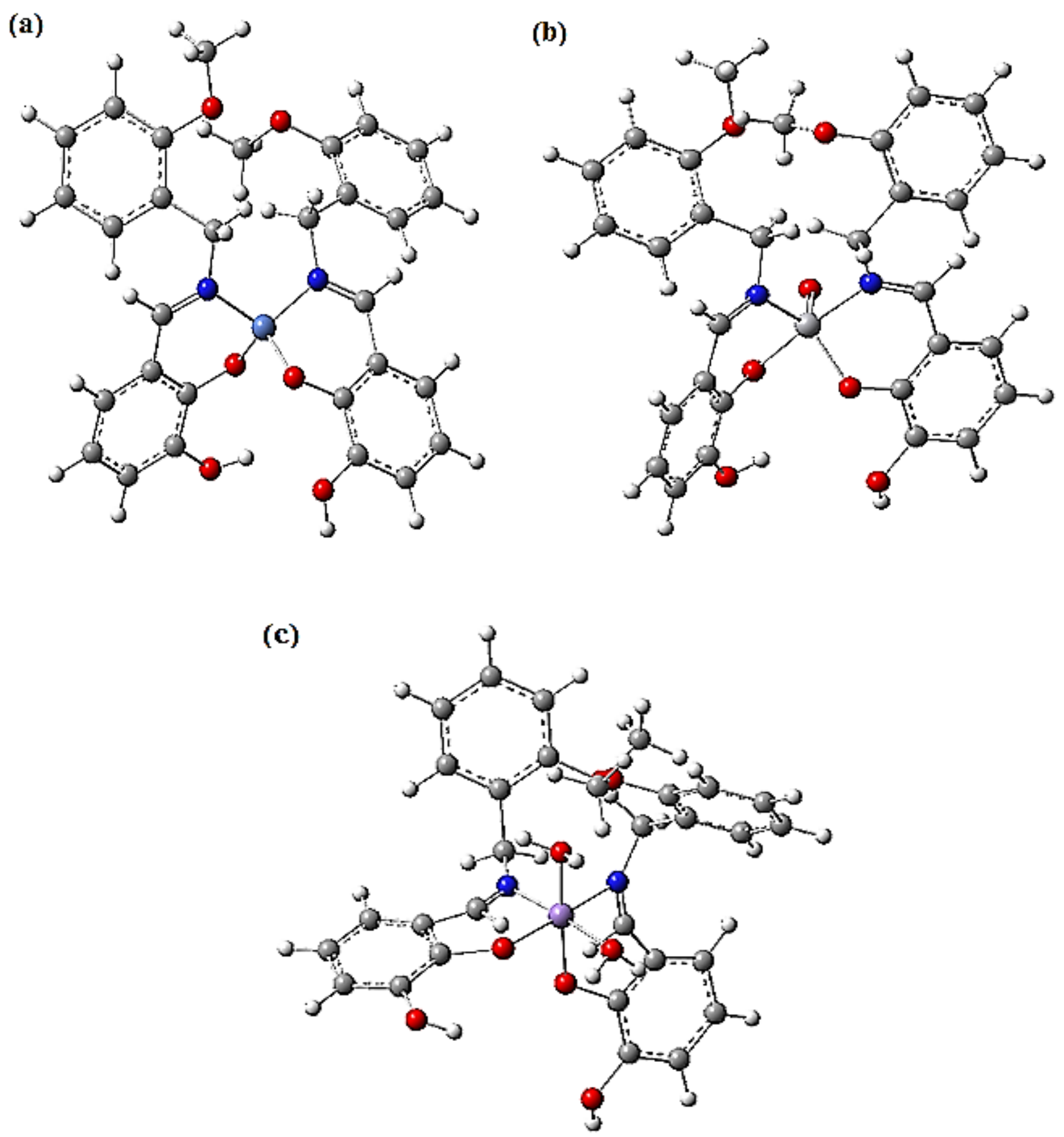

Figure 8. Proposed structures for (a) nickel(II), (b) oxovanadium(IV) and (c) manganese(II) complexes, as optimized by DFT calculations. 


\subsection{Frontiers Molecular Orbitals (FMOs)}

The HOMO-LUMO are the main orbitals that take part in the chemical stability of a molecule, so the calculation of their energy helps to characterize its chemical reactivity. The HOMO highlight is the orbital that primarily acts as electron donor and the LUMO is the orbital that largely acts as electron acceptor, and the gap between HOMO and LUMO orbitals is the parameter related with the molecular chemical stability [49]. The energies of the HOMO and the LUMO orbitals were investigated by using DFT with the standard B3LYP/6-31G(d,p) model. Figure 9 shows the complexes molecular structures deduced from calculations, where the positive phases are presented in red and the negative ones in green.

In addition, Table 6 summarizes the calculated HOMO and LUMO energies and some related characteristic physicochemical parameters (such as, energy gap $(\Delta \mathrm{E})$, electronic chemical potential $(\mu)$, hardness $(\eta)$ and electrophilicity $(\omega)$ ) of the Schiff base ligand HL and its complexes. The chemical hardness is associated with the stability and reactivity of a chemical system. According to frontier molecular orbitals, chemical hardness corresponds to the energy gap between HOMO and LUMO. As the energy gap increases, the molecule becomes harder and more stable (less reactive). On the other hand, the higher the electronic chemical potential (absolute values), the higher the reactivity. As observed in Table 6, the energy gap, chemical hardness and electronic chemical potential values calculated for the complexes are generally lower than that for the ligand. This infers that the ligand is stabilized upon complex formation. In this sense, the results suggest that the $\mathrm{VO}$ (II) complex may be the most stable (according to larger $\Delta \mathrm{E}$ and $\eta$ ), followed by the $\mathrm{Mn}(\mathrm{II})$ and $\mathrm{Ni}(\mathrm{II})$ ones.

Table 6. HOMO, LUMO, energy gap $(\Delta \mathrm{E})$, chemical hardness $(\eta)$, electronic chemical potential $(\mu)$ and electrophilicity $(\omega)$ calculated for the ligand and its corresponding $\mathrm{Ni}(\mathrm{II}), \mathrm{VO}(\mathrm{II})$ and $\mathrm{Mn}$ (II) complexes. All values were calculated in $\mathrm{eV}$ unit.

\begin{tabular}{|l|c|c|c|c|c|c|}
\hline Compound & HOMO & LUMO & $\Delta \mathbf{E}^{\mathbf{a}}$ & $\boldsymbol{\eta}^{\mathbf{b}}$ & $\boldsymbol{\mu}^{\mathbf{c}}$ & $\omega^{\mathbf{d}}$ \\
\hline HL & -5.09 & -0.34 & 4.75 & 2.37 & -2.71 & 1.54 \\
\hline Ni(II) complex & -3.88 & -0.87 & 3.06 & 1.53 & -2.37 & 1.83 \\
\hline VO(IV) complex & -6.59 & -5.50 & 1.08 & 0.54 & -6.04 & 33.77 \\
\hline Mn(II) complex & -3.80 & -1.01 & 2.78 & 1.39 & -2.40 & 2.11 \\
\hline
\end{tabular}

${ }^{\mathrm{a}} \Delta \mathrm{E}=\mathrm{LUMO}-\mathrm{HOMO} ;{ }^{\mathrm{b}} \eta=1 / 2\left(\mathrm{E}_{\mathrm{LUMO}}-\mathrm{E}_{\mathrm{HOMO}}\right),{ }^{\mathrm{c}} \mu=1 / 2\left(\mathrm{E}_{\mathrm{HOMO}}+\mathrm{E}_{\mathrm{LUMO}}\right),{ }^{\mathrm{d}} \omega=\mu^{2} / 2 \eta$. 


\section{Energy $(\mathrm{eV})$}

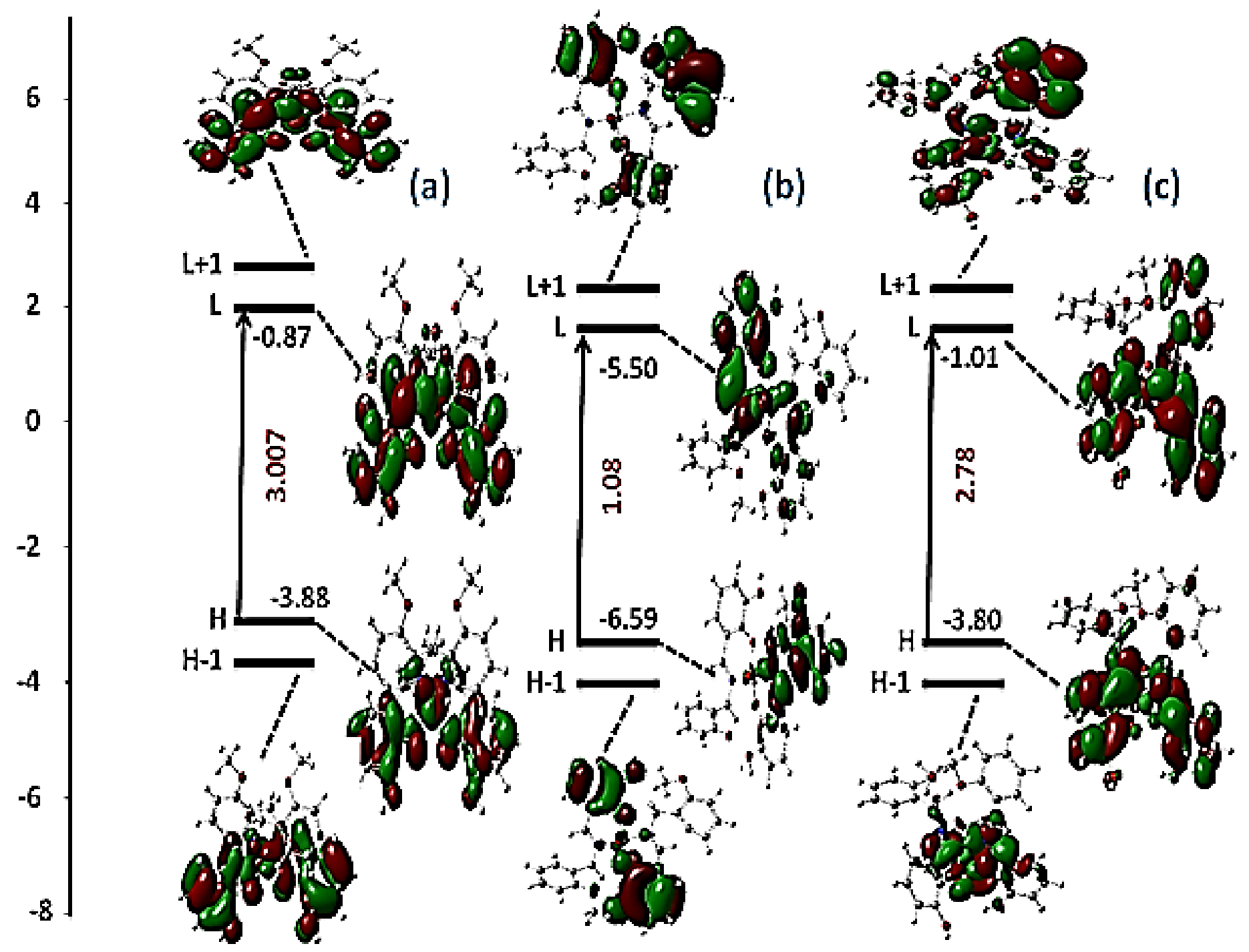

Fig. 9. Energy diagram and representation of the HOMO (H) and LUMO (L) energy levels, energy gaps and frontier molecular orbitals for (a) nickel(II), (b) oxovanadium(IV) and (c) manganese(II) complexes.

The electronic dipole moment $\left\{\mu_{\mathrm{i}}(\mathrm{i}=\mathrm{x}, \mathrm{y}, \mathrm{z})\right.$ and total dipole moment $\left.\mu_{\text {tot }}\right\}$ for title compounds are collected in Table 7. The results indicate that the value of dipole moment of VO(IV) complex (7.7547 debye) $>\mathrm{Mn}$ (II) complex (6.9321 debye) $>\mathrm{Ni}$ (II) complex (6.2395 debye) $>\mathrm{HL}$ (2.8732 debye). It is well known that a higher value of dipole moment is important for more active Non-Linear Optical (NLO) 
properties. NLO effects have been extensively studied over the last decades. Thus, molecules exhibiting large hyperpolarizabilities have a strong NLO potential and could be used, under certain conditions, for optoelectronics and a variety of optical devices [50]. Some quantum chemical descriptors which are the mean electric polarizability $(\alpha)$, the anisotropy of the polarizability $(\Delta \alpha)$ and first order hyperpolarizability ( $\beta$ ) have been used for explaining the NLO properties in many computational studies [51]. In the present study, the $\alpha, \Delta \alpha$ and $\beta$ values were theoretically predicted (Table 7). According to these calculations (at the same level of theory as well as same basis set $6-31 \mathrm{G}(\mathrm{d}, \mathrm{p})$ ), the values of $\alpha$ and $\Delta \alpha$ found for the VO(IV) complex are higher than for the other compounds. This is in line with the found lower frontier orbital energy gap ( $\Delta \mathbf{E}$ ) of the VO(IV) complex (Table 6). On the other hand, in agreement with its higher dipole moment, the lower $\beta$ value obtained for the VO(IV) complex indicates that the this compound possesses better NLO properties than the others, so it becomes a potential candidate for NLO applications.

Table 7 The electric dipole moments ( $\mu$, in debyes), polarizabilities ( $\alpha$, in a.u) and hyperpolarizabilities $(B$, in a.u) components and total values, as well as the anisotropy of the polarizability $(\Delta \alpha)$ of the HL ligand and the $\mathrm{Ni}(\mathrm{II}), \mathrm{VO}(\mathrm{IV})$ and $\mathrm{Mn}(\mathrm{II})$ complexes calculated with B3LYP/6-31G(d,p).

\begin{tabular}{crrrr}
\hline Parameters & HL & $\begin{array}{r}\text { Ni(II) } \\
\text { complex }\end{array}$ & $\begin{array}{r}\text { VO(IV) } \\
\text { complex }\end{array}$ & $\begin{array}{r}\text { Mn(II) } \\
\text { complex }\end{array}$ \\
\hline$\mu_{\mathrm{x}}$ & -2.4198 & 2.1894 & -5.0781 & -5.6321 \\
$\mu_{\mathrm{y}}$ & -2.6969 & 2.0836 & -5.8607 & -3.1826 \\
$\mu_{\mathrm{z}}$ & 0.4168 & 2.0253 & -0.0150 & 2.4910 \\
$\boldsymbol{\mu}_{\mathrm{tot}}$ & $\mathbf{2 . 8 7 3 2}$ & $\mathbf{6 . 2 3 9 5}$ & $\mathbf{7 . 7 5 4 7}$ & $\mathbf{6 . 9 3 2 1}$ \\
\hline$\alpha_{\mathrm{xx}}$ & -99.9058 & -205.1184 & -247.6975 & -214.1616 \\
$\alpha_{\mathrm{yy}}$ & -96.0414 & -210.9704 & -232.5401 & -220.8387 \\
$\alpha_{\mathrm{zz}}$ & -109.8336 & -225.7951 & -231.2249 & -226.6761 \\
$\alpha_{\mathrm{xy}}$ & 2.7832 & 0.8714 & 11.4563 & 9.8801 \\
$\alpha_{\mathrm{xz}}$ & 1.4939 & 8.0543 & -16.0336 & 17.3521 \\
$\mathrm{~A}_{\mathrm{yz}}$ & -0.2142 & -10.1195 & 17.7394 & 15.3022 \\
$\boldsymbol{\alpha}$ & $\mathbf{- 1 0 1 . 9 2 7 8}$ & $\mathbf{- 2 1 3 . 9 6 1 3}$ & $\mathbf{- 2 3 7 . 1 5 4 1}$ & $\mathbf{- 2 2 0 . 5 5 8}$ \\
$\Delta \boldsymbol{\alpha}^{\circ}$ & $\mathbf{1 3 . 5 2 4 8}$ & $\mathbf{2 9 . 1 5 3 6}$ & $\mathbf{4 8 . 7 2 9 5}$ & $\mathbf{4 5 . 0 4 8 5}$ \\
\hline
\end{tabular}




\begin{tabular}{lrrrr}
\hline$\beta_{\mathrm{xxx}}$ & 64.8155 & 64.8155 & -274.9187 & -0.8224 \\
$\beta_{\mathrm{xxy}}$ & -13.9245 & -13.9245 & -132.9412 & -24.9312 \\
$\beta_{\mathrm{xyy}}$ & -8.9802 & -8.9882 & 16.3759 & -43.6176 \\
$\beta_{\mathrm{yyy}}$ & 15.4898 & 15.4898 & 100.6738 & 166.7716 \\
$\beta_{\mathrm{xxz}}$ & -39.0351 & -39.0351 & 31.0844 & -10.8502 \\
$\beta_{\mathrm{xyz}}$ & -6.7001 & -6.7001 & 67.2330 & -18.6250 \\
$\beta_{\mathrm{yyz}}$ & 4.7512 & 4.7512 & 3.6709 & -4.9014 \\
$\beta_{\mathrm{xzz}}$ & -13.9245 & -13.9245 & 27.0438 & -6.0415 \\
$\beta_{\mathrm{yzz}}$ & 8.4708 & 8.4708 & -11.9078 & -48.6632 \\
$\beta_{\mathrm{zzz}}$ & 6.8008 & 6.8008 & 34.4736 & -44.3838 \\
$\boldsymbol{\beta}_{\text {tot }}$ & $\mathbf{5 1 . 1 1 3 2}$ & $\mathbf{5 1 . 1 0 6 6}$ & $\mathbf{2 4 5 . 1 8 7 0}$ & $\mathbf{1 2 3 . 8 6 4 2}$ \\
\hline
\end{tabular}



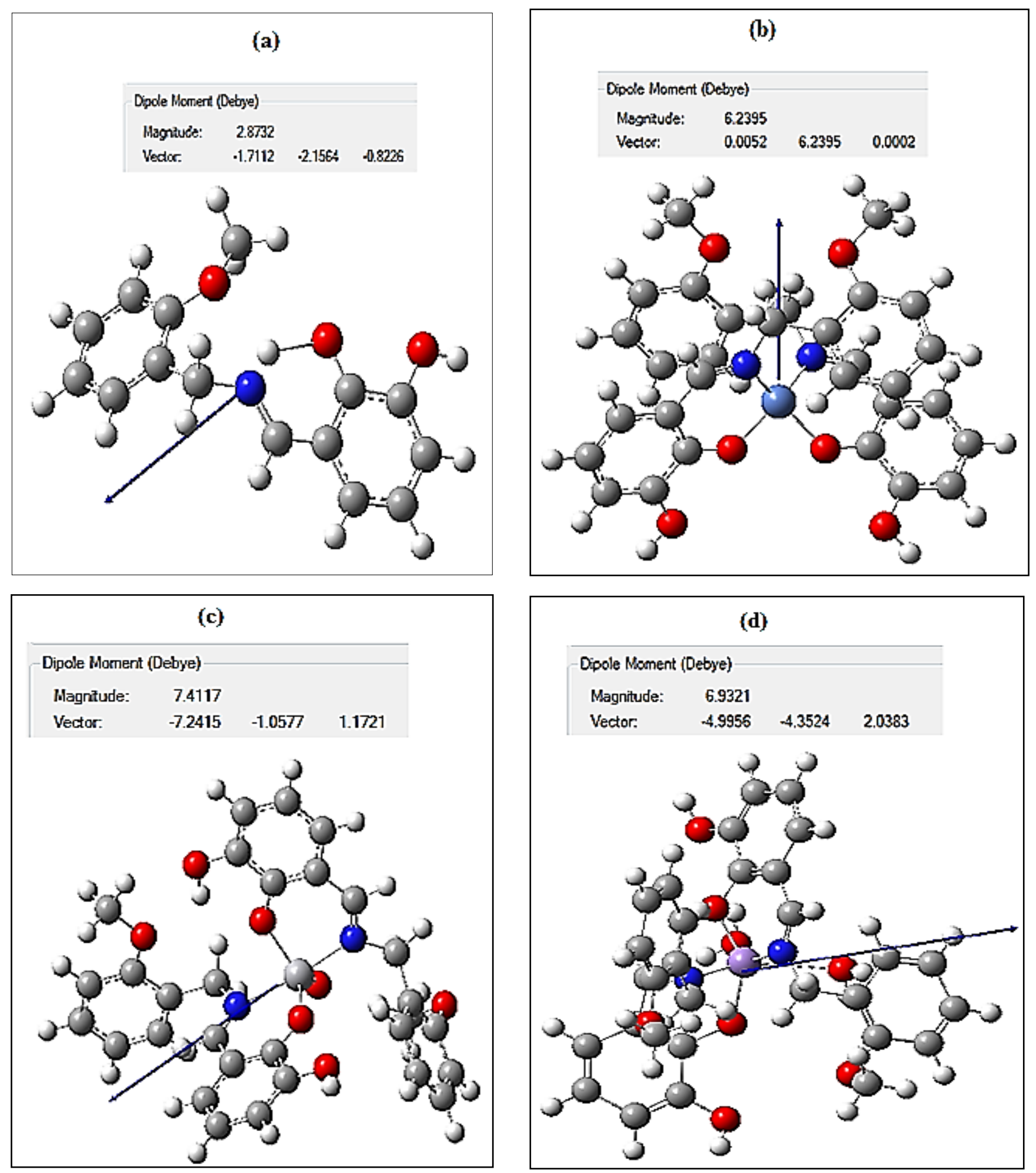

Figure 10. Direction of dipole moment of Ground state optimized structures for the (a) HL ligand and the (b) $\mathrm{Ni}(\mathrm{II})$, (c) $\mathrm{VO}(\mathrm{IV})$ and (d) $\mathrm{Mn}(\mathrm{II})$ complexes. 


\subsection{Molecular Electrostatic Potential (MEP)}

The MEP is a property useful to study the attacking sites for electrophilic and nucleophilic substitution reactions [52,53]. Figure 11 displays the total electron density surfaces mapped with electrostatic potential of the ligand $\mathbf{H L}$ and their complexes. The different values of the electrostatic potential at the surface are represented by different colors. Thus, the negative regions represented by the red color are the preferable sites for electrophilic attack. The results show that these negative potentials are generated over the more electronegative oxygen and nitrogen atoms, whereas the $\mathrm{H}$-atoms exhibiting a positive potential region in the structures (represented by the blue color) are favorable sites for nucleophilic attack. These last regions are located around hydrogen and carbon atoms. Finally, the yellow color indicates the slightly rich electron regions and the green one reflects more neutral zones.

The obtained MEP maps suggest that while the HL ligand and Ni(II) complex may participate in both electrophilic and nucleophilic reactions, the VO(IV) and Mn(II) complexes seem to better take part in electrophilic processes.

(a)
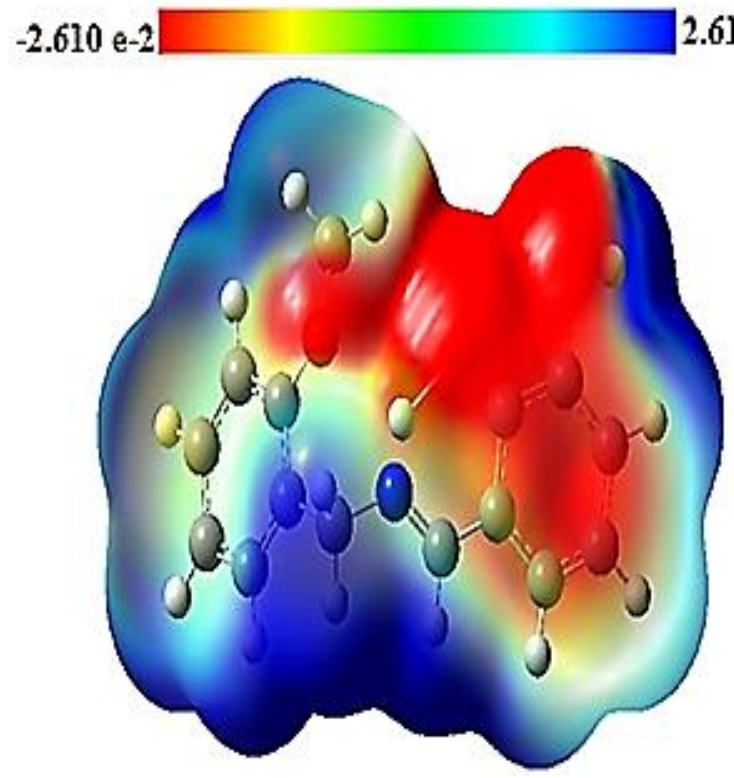

(b)
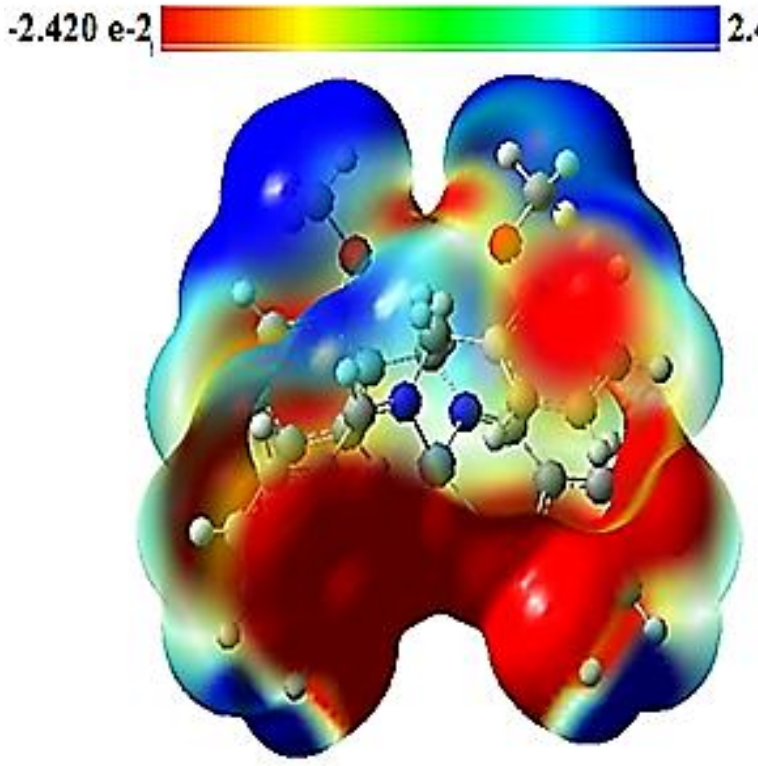
(c)

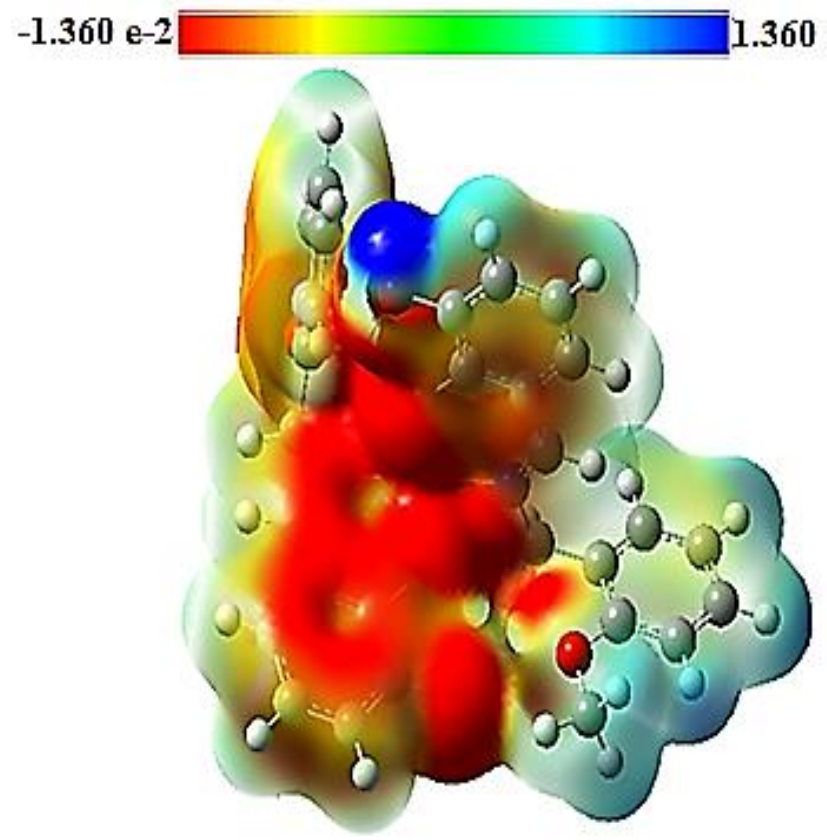

(d)

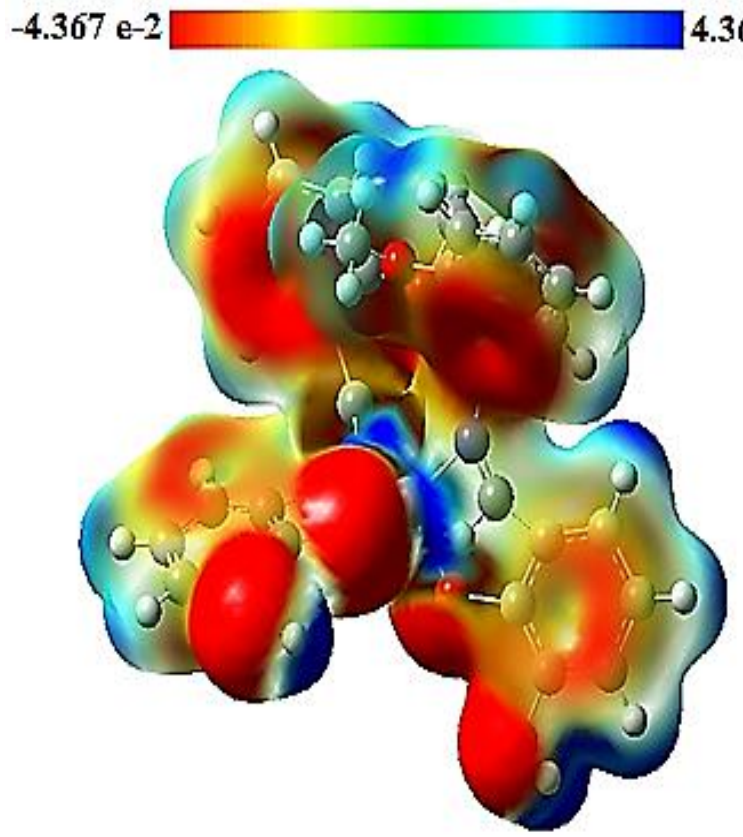

Figure 11. Molecular electrostatic potential maps for the (a) HL ligand and the (b) Ni(II), (c) VO(IV) and (d) $\mathrm{Mn}(\mathrm{II})$ at the B3LYP/6-31G(d,p) level of theory.

\section{Conclusion}

In summary, we have successfully synthesized and characterized three new Schiff-base complexes of nickel(II), manganese(II) and oxovanadium(IV). From the results of FT-IR, UV-Vis, LC-MS and elemental analysis, the molecular structures of the complexes have been proposed. The bis-bidentate Schiff-base ligands coordinate to the $\mathrm{VO}$ (IV), $\mathrm{Mn}$ (II) and $\mathrm{Ni}$ (II) ions in a tetradentate mode ( $\mathrm{ML}_{2}$ ) using the azomethine $\mathrm{N}$ and enol $\mathrm{O}$ atoms. The assignment of a square-planar geometry for $\mathrm{Ni}(\mathrm{II})$, a squarepyramidal geometry for the $\mathrm{VO}$ (IV) and an octahedral geometry for the $\mathrm{Mn}(\mathrm{II})$, is supported by electronic absorption and infrared spectral measurements, as well as quantum chemical calculations. The electrochemical characterization shows that the complexes exhibit redox activity associated to their metal centers. Moreover, the calculated molecular properties suggest that the VO(II) complex may be the most stable compound and that exhibiting best NLO properties. Hence, the present study shows a simple method 
for the synthesis of some bis-bidentates Schiff base complexes with interesting properties to be used in electrochemical and other applications.

\section{Knowledgements}

The authors would like to thank the MESRS and DG-RSDT (Ministère de l'Enseignement Supérieur et de la Recherche Scientifique et la Direction Générale de la Recherche et du Développement Technologique-Algérie) for their financial support. Financial support from the Ministerio de Economía y Competitividad (Spain) and FEDER funds (MAT2016-76595-R and RYC-2017-23618) is also gratefully acknowledged.

\section{References}

[1] H. Schiff, Untersuchungenüber Salicinderivate. Ann. Chem., 150 (1869) 193-200.

[2] V.M. Leovac, D.M. Joksovic, V. Divjakovic, L.S. Jovanovic, Z. Saranovic, A. Pevec, Synthesis, spectroscopic and X-ray characterization of a copper(II) complex with the Schiff base derived from pyridoxal and aminoguanidine: NMR spectral studies of the ligand, J. Inorg. Biochem., 101 (2007) 10941097.

[3](A) E.N. Jacobsen, \& M.H. Wu, in Comprehensive Asymmetric Catalysis: Asymmetric Synthesis and Induction Catalysts, ed. Yamamoto, H. (Springer, Berlin), 2 (1999) 649-677; (B) T. Katsuki, in Catalytic Asymmetric Synthesis, ed. Ojima, I. (Wiley-VCH, New York), (2000) 287-325; (C) E. N. Jacobsen, in Catalytic Asymmetric Synthesis, ed. Ojima, I. (VCH, New York), (1993) 159-202.

[4](A) J. Tisato, F. Refosco, F. Bandoli, Structural survey of technetium complexes, Coord. Chem. Rev., 135 (1994) 325-397; (B) I.N. Booysen, S. Maikoo, M.P. Akerman, B. Xulu, Novel ruthenium (II) and (III) compounds with multidentate Schiff base chelates bearing biologically significant moieties, Polyhedron, 79 (2014) 250-257.

[5] D. Aggoun, A. Ourari, R. Ruiz-Rosas, E. Morallon, A selective naked-eye chemosensor derived from 2-methoxybenzylamine and 2,3-dihydroxybenzaldehyde: synthesis, spectral characterization and electrochemistry of its bis-bidentates Schiff bases metal complexes, Spectrochim. Acta A, 184 (2017) 299-307. 
[6] A.A. Alshaheri, M.I.M. Tahir, M.B. Abdul Rahman, T. Begum, T.A. Saleh, Synthesis, characterization and catalytic activity of dithiocarbazate Schiff base complexes in oxidation of cyclohexane, J. Mol. Liq., 240 (2017) 486-496

[7] A. Ourari, M. Khelafi, D. Aggoun, A. Jutand, C. Amatore, Electrocatalytic oxidation of organic substrates with molecular oxygen using tetradentate ruthenium(III)-Schiff base complexes as catalysts, Electrochim. Acta, 75 (2012) 366-370.

[8] F. Heshmatpour, S. Rayati, M.A. Hajiabbas, P. Abdolalian, B. Neumüller, Copper(II) Schiff base complexes derived from 2,20-dimethyl-propandiamine: Synthesis, characterization and catalytic performance in the oxidation of styrene and cyclooctene, Polyhedron, 31 (2012) 443-450.

[9] A. Ghaffari, M. Behzad, M. Pooyan, H.A. Rudbari, G. Bruno, Crystal structures and catalytic performance of three new methoxy substituted salen type nickel(II) Schiff base complexes derived from meso-1,2-diphenyl-1,2-ethylenediamine, J. Mol. Struct., 1063 (2014) 1-7.

[10] S. Ilhan, H. Baykara, A. Oztomsuk, V. Okumus, A. Levent, M.S. Seyitoglu, S. Ozdemir, Synthesis and characterization of 1,2-bis(2-(5-bromo-2 hydroxybenzilidenamino)-4-chlorophenoxy) ethane and its metal complexes: An experimental, theoretical, electrochemical, antioxidant and antibacterial study, Spectrochim. Acta A, 118 (2014) 632-642.

[11] S. Mohebbi, S. Eslami, Electrocatalytic oxidation of 2-mercaptoethanol using modified glassy carbon electrode by MWCNT in combination with unsymmetrical manganese (II) Schiff base complexes, Mate. Res. Bull., 66 (2015) 219-225.

[12] C.R. Bhattacharjee, P. Goswami, M. Sengupta, Synthesis, electrochemical and antimicrobial studies of mono and binuclear iron(III) and oxovanadium(IV) complexes of [ONO] donor tridentate Schiff-base ligands, J. Coord. Chem., 63 (2010) 3969-3980.

[13] A. Kamath, N.V. Kulnarni, P. P Netalkar, V.K. Revankar, Phenoxide bridged tetranuclear Co(II), $\mathrm{Ni}(\mathrm{II}), \mathrm{Cu}(\mathrm{II})$ and $\mathrm{Zn}(\mathrm{II})$ complexes: Electrochemical, magnetic and antimicrobial studies, Spectrochim. Acta A, 79 (2011) 1418-1424.

[14] K.C. Gupta and A.K. Sutar, Catalytic activities of Schiff base transition metal complexes, Coord. Chem. Rev., 252 (2008) 1420-1450.

[15] D.A. Atwood and M.J. Harvey, Group 13 compounds incorporating Salenligands, Chem. Rev., 101 (2001) 37-52. 
[16] N. Yoshida, K. Ichikawa and M. Shiro, Supramolecular motifs in metal complexes of Schiff bases. Part 5. Zinc(II)-assisted self-assembly of some bis- $N, N$ - and $N, O$-bidentate Schiff bases and chiral packing modes in solid state, J. Chem. Soc., Perkin Trans., 2 (2000) 17-26.

[17] H. Hosseini-Monfared, R. Bikas, P. Mahboubi-Anarjan, A.J. Blake, V. Lippolis, N.B. Arslan, C. Kazak, Oxidovanadium(V) complexes containing hydrazone based O,N,O-donor ligands: Synthesis, structure, catalytic properties and theoretical calculations, Polyhedron, 69 (2014) 90-102.

[18] A. Ourari, I. Bougossa, S. Bouacida, D. Aggoun, R. Ruiz-Rosas, E. Morallon, H. Merazig, Synthesis, characterization and X-ray crystal structure of novel nickel Schiff base complexes and investigation of their catalytic activity in the electrocatalytic reduction of alkyl and aryl halides, J. Iran. Chem. Soc.,14 (2017) 703-715.

[19] W. Kohn, L.J. Sham, Self-Consistent Equations Including Exchange and Correlation Effects, Phys.Rev,140 (1965) 1133-1138.

[20] A.D. Becke, Density-functional thermochemistry. III. The role of exact exchange, J. Chem. Phys, 98 (1993) 648-5652.

[21] C. Lee, W. Yang, R.G. Parr, Development of the Colle-Salvetti correlation-energy formula into a functional of the electron density, Phys. Rev, 37 (1998) 785-789.

[22] B. Miehlich, A. Savin, A. Stoll, H. Preuss, Results obtained with the correlation energy density functionals of becke and Lee, Yang and Parr, Chem. Phys. Lett, 157 (1989) 200-206.

[23] B. Bouzerafa, A. Ourari, D. Aggoun, R. Ruiz-Rosas, Y. Ouennoughi, E. Morallon, Novel nickel(II) and manganese(III) complexes with bidentate Schiff-base ligand: synthesis, spectral, thermogravimetry, electrochemical and electrocatalytical properties, Res. Chem. Intermed., 42 (2016) 4839-4858.

[24] A. Ourari, D. Aggoun, Synthesis and spectral analysis of $\mathrm{N}$-substituted pyrrole salicylaldehyde derivatives-electropolymerization of a new nickel(II)-Schiff base complex derived from 6-[3'-N-pyrrolpropoxy]-2 -hydroxyacetophenone and 1,2-diaminoethane, J. Iran. Chem. Soc., 12 (2015) 1893-1904.

[25] R. Aurkie, M.G. Rosair, R. Kadam, S. Mitra, Three new mono- di-trinuclear cobalt complexes of selectively and non-selectively condensed Schiff bases with $\mathrm{N}_{2} \mathrm{O}$ and $\mathrm{N}_{2} \mathrm{O}_{2}$ donor sets: syntheses, structural variations. EPR DNA Bind Stud, Polyhedron, 28 (2009) 796-806.

[26] R.N. Egekenze, Y. Gultneh, R. Butcher, $\mathrm{Mn}(\mathrm{III})$ and $\mathrm{Mn}$ (II) complexes of tridentate Schiff base ligands; synthesis, characterization, structure, electrochemistry and catalytic activity, Inorg. Chim. Acta, 478 (2018) 232-242. 
[27] A.M. Fayed, S.A. Elsayed, A.M. El-Hendawy, M.R. Mostafa, Complexes of cisdioxomolybdenum(VI) and oxovanadium(IV) with a tridentate ONS donor ligand: Synthesis, spectroscopic properties, X-ray crystal structure and catalytic activity, Spectrochim. Acta A, 129 (2014) 293-302.

[28] B. Bouzerafa, D. Aggoun, Y. Ouennoughi, A. Ourari, R. Ruiz-Rosas, E. Morallon, M.S. Mubarak, Synthesis, spectral characterization and study of thermal behavior kinetics by thermogravimetric analysis of metal complexes derived from salicylaldehyde and alkylamine, J. Mol. Struct., 1142 (2017) 48-57.

[29] M. Salehi, F. Faghani, M. Kubicki, M. Bayat, New complexes of $\mathrm{Ni}(\mathrm{II})$ and $\mathrm{Cu}(\mathrm{II})$ with tridentate ONO Schiff base ligand: synthesis, crystal structures, electrochemical and theoretical investigation, J. Iran. Chem. Soc., 15 (2018) 2229-2240.

[30] M.M. Tulu and A.M. Yimer, Catalytic Studies on Schiff Base Complexes of Co(II) and Ni(II) Using Benzoylation of Phenol, Mod. Chem. Appl., 6 (2018) 1-6.

[31] M.R. Bermejo, M.I. Fernández, E. Gómez-Fórneas, A. González-Noya, M. Maneiro, R. Pedrido, and M.J. Rodríguez, Self-Assembly of Dimeric MnIII-Schiff-Base Complexes Tuned by Perchlorate Anions, Eur. J. Inorg. Chem., (2007) 3789-3797.

[32] G. Gonzalez-Riopedre, M.I. Fernandez-Garcıa, A.M. Gonzalez-Noya, M.A. Vazquez-Fernandez, M.R. Bermejo and M. Maneiro, Manganese-Schiff base complexes as catalysts for water photolysis, Phys. Chem. Chem. Phys., 13 (2011) 18069-18077.

[33] M. Tümer, Synthesis and Spectral Characterization of Metal Complexes Containing Tetra- and Pentadentate Schiff Base Ligands, Synth. React. Inorg. Met. Org. Chem. 30 (2000) 1139-1158.

[34] P.S. Prasad, P. Kumar, K. Bharathi, V. Narayanan, Synthesis of Vanadium (III) Schiff Base Complex and its Electrocatalytic Sensing Application, Mechanics, Mater. Sci. Eng., (2017) 130-134.

[35] A.R. Cowley, J.R. Dilworth, P.S. Donnelly, A.D. Gee and J.M. Heslop, Acetylacetonate bis(thiosemicarbazone) complexes of copper and nickel: towards new copper radiopharmaceuticals, Dalton Trans., (2004) 2404-2412.

[36] B. Debajani, L.R. Ashray, K. Arvind, Synthesis, and characterization of low- and high-spin manganese(II) complexes of polyfunctional adipoyldihydrazone: Effect of coordination of N-donor ligands on stereo-redox chemistry, J. Mol. Struct., 1092 (2015) 122-129.

[37] A.A. Hassoon, N.S. Al-Radadi, N. Nawar, M.M. Mostafa, New Square-Pyramidal Oxovanadium (IV) Complexes Derived from Polydentate Ligand (L1), J. Inorg. Chem., 6 (2016) 23-65. 
[38] M. Ikram, S. Rehman, M. Ali, Faridoon, C. Schulzke, R.J. Baker, A.J. Blake, K. Malook, H. Wong, S.-Ur-Rehman, Urease and $\alpha$-chymotrypsin inhibitory activities of transition metal complexes of new Schiff base ligand: Kinetic and thermodynamic studies of the synthesized complexes using TG-DTA pyrolysis, Thermochim. Acta, 562 (2013) 22-28.

[39] E.M. Zayed, G.G. Mohamed, A.M.M. Hindy, Transition metal complexes of novel Schiff base Synthesis, spectroscopic characterization, and in vitro antimicrobial activity of complexes, J. Therm. Anal. Calorim., 120 (2014) 893-903.

[40] A.H. Kianfar, V. Sobhani, M. Dostani, M. Shamsipur, M. Roushani, Synthesis, spectroscopy, electrochemistry and thermal study of vanadyl unsymmetrical Schiff base complexes, Inorg.Chim. Acta, 365 (2011) 108-112.

[41] M. Pooyan, A. Ghaffari, M. Behzad, H. Amiri Rudbari, G. Bruno, Tetradentate $\mathrm{N}_{2} \mathrm{O}_{2}$ type Nickel(II) Schiff base complexes derived from meso-1,2-diphenyle-1,2-ethylenediamine: synthesis, characterization, crystal structures, electrochemistry, and catalytic studies, J. Coord. Chem. 66 (2013) 4255-4267.

[42] D. Chatterjee, A. Mitra, Olefin epoxidation catalysed by Schiff-base complexes of Mn and Ni in heterogenised-homogeneous systems, J. Mol. Catal. A: Chem. 144 (1999) 363-367.

[43] N. Bréfuel, C. Lepetit, S. Shova, F. Dahan, J.-P. Tuchagues, Complexation to Fe(II), Ni(II), and $\mathrm{Zn}$ (II) of multidentate ligands resulting from condensation of 2-pyridinecarboxaldehyde with alpha,omega-triamines: selective imidazolidine/hexahydropyrimidine ring opening revisited, Inorg. Chem. 44 (2005) 8916-8928.

[44] J.L.N. Xavier, E. Ortega, J.Z. Ferreira1, A.M. Bernardes, V. Pérez-Herranz, An electrochemical Study of Phenol Oxidation in Acidic Medium, Int. J. Electrochem. Sci. 6 (2011) 622-636.

[45] M.H. Habibi, E. Askari, M. Amirnasr, A. Amiri, Y. Yamane, T. Suzuki, Syntheses, spectral, electrochemical and thermal studies of mononuclear manganese(III) complexes with ligands derived from 1,2-propanediamine and 2-hydroxy-3 or 5-methoxybenzaldehyde: Self-assembled monolayer formation on nanostructure zinc oxide thin film, Spectrochim. Acta A, 79 (2011) 666-671.

[46] K. Ramesh, T. K. Lal and R. N. Mukherjee, Synthesis, Spectra and Electrochemistry of NonOxovanadium(IV) Bischelates of Tridentate Schiff Base Ligands. Magnetism of Bis[N-(2Hydroxyphenyl)-5- Methylsalicylideniminato]Vanadium(IV), Polyhedron, 11 (1992) 3083-3089.

[47] Pierluca Galloni, Alessia Coletti, Barbara Floris, Valeria Conte, Electrochemical properties of VO salen complexes, Inorg. Chim. Acta, 240 (2014) 144-148. 
[48] J.T. Lundquist, JR. and Richard S. Nicholson, Theory of the potential step-linear scan electrolysis method with a comparison of rate constants determined electrochemically and by classical methods, J. Electroanal. Chem.,16 (1968) 445-456.

[49] Y. Sun, X. Chen, L. Sun, X. Guo, W. Lu, Nanoring structure and optical properties of Ga8As8, J. Chem. Phys. Lett. 381 (2003) 397-403.

[50] M. Albota, D. Beljonne, J.L. Brédas, J.E. Ehrlich, J.Y. Fu, A.A. Heikal, S.E. Hess, T. Kogej, M.D. Levin, S.R. Marder, D. Mc Cordmaughon, J.W. Perry, H. Rockel, M. Rumi, C. Subramaniam, W.W. Webb, I.L. Wu and C. Xu, Design of Organic Molecules with Large Two-Photon Absorption Cross Sections, Science, 281 (1998) 1653-1656.

[51] K. Gokula Krishnan, R. Sivakumar, V. Thanikachalam, H. Saleem, M. Arockia doss, Synthesis, spectroscopic investigation and computational study of 3-(1-(((methoxycarbonyl)oxy)imino)ethyl)-2Hchromen-2-one, Spectrochim. Acta Part A, 144 (2015) 29-42.

[52] J.S. Murray, K. Sen, Molecular Electrostatic Potentials, Concepts and Applications, Elsevier, Amsterdam, 1996.

[53] P. Politzer, D.G. Truhlar, Chemical Application of Atomic and Molecular Electrostatic Potentials, Plenum, New York, 1981 